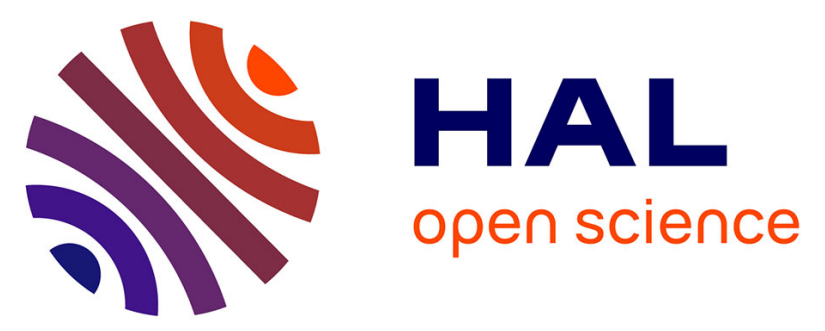

\title{
L'écriture à La Graufesenque (Millau, Aveyron): les vaisselles sigillées inscrites comme sources d'information sur les structures professionnelles
}

Colette Bémont

\section{- To cite this version:}

Colette Bémont. L'écriture à La Graufesenque (Millau, Aveyron): les vaisselles sigillées inscrites comme sources d'information sur les structures professionnelles. Gallia - Archéologie de la France antique, 2004, L'écriture dans la société gallo-romaine, 61, pp.103-131. 10.3406/galia.2004.3189 . hal-01910972

\section{HAL Id: hal-01910972 \\ https://hal.science/hal-01910972}

Submitted on 29 Jan 2020

HAL is a multi-disciplinary open access archive for the deposit and dissemination of scientific research documents, whether they are published or not. The documents may come from teaching and research institutions in France or abroad, or from public or private research centers.
L'archive ouverte pluridisciplinaire HAL, est destinée au dépôt et à la diffusion de documents scientifiques de niveau recherche, publiés ou non, émanant des établissements d'enseignement et de recherche français ou étrangers, des laboratoires publics ou privés.

\section{(ㅇ)(1) $\$$}

Distributed under a Creative Commons Attribution - NonCommercial - NoDerivatives 44.0 


\section{L'ÉCRITURE À LA GRAUFESENQUE (Millau, AveYron)}

\section{Les vaisselles sigillées inscrites comme sources d'information sur les structures professionnelles}

\section{Colette BÉMONT}

Mots-clés. Gaule romaine, Haut-Empire, industrie, céramique sigillée, structures professionnelles, pratiques ouvrières, écriture, signatures, comptes de potiers, vocabulaire gallo-romain, noms de vases, mesures et modules.

Résumé. Deux types de documents épigraphiques liés à la production et à la diffusion massives de vaisselles de table à Condatomagus/La Graufesenque (Millau, Aveyron) entre le début du $\mathrm{r}^{r}$ s. et le milieu du $\mathrm{It}^{r}$ : les marques de fabrique (estampillées ou inscrites) sur les vases ou moules; les graffites de potiers (environ 200 pièces comptables à usage interne établies au moment de la cuisson) ont fait l'objet de récentes mises à jour. Le contenu de ces témoignages donne lieu à une rérision critique globale des problèmes posés par le personnel des ateliers (alphabétisation, romanisation du langage, statuls sociaux), par l'organisation de la fabricalion (structures des officines et finalité du marquage, hiérarchie des fonctions et partage du travail, coordination el usage d'outils collectifs, bases contractuelles de la coopération, rythme de la fabrication) el par la réduction à partir de la fin du fr's. d'une des sources documentaires : l'estampillage des produits.

Key-words. Roman Gaul, Principate, industry, samian potlery, professional structures, craft practices, uriting, signatures, potters accounts, Gallo-Roman vocabulary, vessel names, measures and moduli.

Abstract. Two kinds of epigraphic documents related to production and mass distribution of tableware at Condatomagus/La Graufesenque (Millau, Aveyron) between the beginning of the $1^{\text {rt }}$ century and mid $2^{\text {nd }}$ century: fabric marks (stamped or inscribed) on pots or moulds. A reassessment of potters' graffiti (about 200 accounts for internal use drawn up before firing) has recently been done. The content of these documents gives way to a general criticism of the problems connected to the workshops staff (teaching to read and write, Romanization of language, social status), to the organization of production (structure of the kilns, purpose of marking, hierarchy of functions and job sharing, co-ordination and utilization of collective tools, contractual bases of cooperation, rate of production) and to the diminution of one of the documentary sources from the end of the $1^{\text {rst }}$ century: stamping of products.

Translation : Isabelle FAUDLET

Schlagwörter. Römisches Gallien, frühe Kaiserzeit, Industrie, Terra Sigillata, Betriebsstrukturen, Arbeitsabläufe, Schrift, Herstellermarken, Töpferrechnungen, gallorömischer Wortschatz, Gefäßnamen, Maße und Module.

Zusammenfassung. Zweierlei Arten von epigraphischen Zeugnissen, die mit der massenhaften Herstellung und Verbreitung von Tafelgeschirr in Condatomagus/La Graufesenque (Millau, Aveyron) vom Anfang des ersten bis zur Mitte des zweiten Jahrh. $n$. Chr. zusammenhängen, stehen im Mittelpunkt neuer Studien : Fabrikmarken, die man als Stempel oder als Aufschriften auf Gefäßen und Formschüsseln findet, sowie die Töpfergraffiti, ungefähr 200 Abrechnungen, die beim Brand zum internen Gebrauch erstellt wurden. Der Inhalt dieser Zeugnisse gibt Anla $\beta$ zu einer neuen kritischen Gesamtschau der Problematik des Personals der Manufakturen (Kenntnis von Schreiben und Lesen, Romanisierung der Sprache, soziale Stellung), der Organisation der Produktion (Struktur der Betriebe und Zweck der Marken, Aufgabenhierarchie und Arbeitsteilung, Koordinierung und Gebrauch gemeinschaftlicher Werkzeuge, Vertragsgrundlagen der Zusammenarbeit, Produktionsrhythmus) und des vom Ende des ersten Jahrh. n. Chr: an zu beobachtenden Versiegens einer der epigraphischen Quellen, nämlich der Stempelung der Produkte. 
Le centre de production de La Graufesenque à Millau (Aveyron) est reconnu comme le principal fournisseur de l'Empire romain en vaisselle sigillée, au $\mathrm{I}^{\mathrm{cr}} \mathrm{s} .{ }^{1+7}$. Il est représenté sur de multiples sites d'achat, principalement de l'Furope occidentale ou centrale et d'Afrique du Nord, par des milliers de vases, reconnaissables dans de très nombreux cas à leur forme et leur aspect, et souvent inscrits. Ces textes se réduisent le plus souvent à des sceaux et des graffites de fabricants, mais consistent aussi parfois en courts messages. L.es ateliers euxmêmes, révélés entre 1862 et 1885 par des fouilles (abbé (érès) dont les résultats et l'extension restent largement inconnus, ont fait au début du $\mathrm{xx}^{*}$ s. l'objet d'explorations plus sérieuses (F. Hermet), insuffisamment décrites, mais dont le mobilier donna lieu à d'importantes publications françaises, anglaises et allemandes. Depuis 1950 ont été entreprises des recherches méthodiques (A. Albenque, I. Balsan, puis A. Vernhet) sur un territoire limité (fig. 56). Ces travaux divers ont heureusement fourni un mobilier abondant et complémentaire : des vases, des outils parfois signés, particulièrement des moules. Ils ont surtout livré des documents paléographiques jusqu'à ce jour exceptionnels ${ }^{148}$ : près de deux cents textes ou fragments manuscrits relatifs au fonctionnement de la production (les graffites de La Graufesenque).

Ces marques ou textes, imprimés ou inscrits avant cuisson, sont de ce fait liés de façon plus ou moins fonctionnelle à un moment de la fabrication. Dans leur ensemble ils méritent l'intérêt dans la mesure où ils témoignent - par la langue, les graphies, les contenus - d'usages locaux dans une région de romanisation assez récente et dans une industrie dont les premiers essais, dans le sud de la Gaule, datent apparemment du règne d'Auguste et l'expansion, visiblement de celui de Claude ${ }^{149}$.

Il serait cependant inutile et hors de propos de reprendre ici les discussions engagées depuis quelques années à la suite des travaux de K. Strobel sur les papyri d'Oxyrhinque et la structure juridique de la production céramique en Égypte au

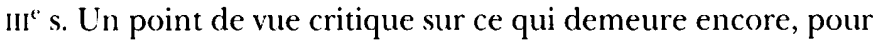
La Graufesenque, un ensemble d'hypothèses a été exposé trop récemment par G. B. Dannell (2002), pour que l'on ajoute,

147. Cette vaisselle de table rouge à enduit argileux fritté imite pour l'essenticl des modèles italiques dont elle reprend, au moins jusqu'au milieu du $\mathrm{I}^{\mathrm{er}}$ s., une partic des formes standardisées, simplement tournées et produites en masse (vases lisses). Less vases ornés, édités en quantité restreinte et tournés dans des moules décorés à l'aide de poinçons, se libèrèrent en revanche rapidement de types italiques complexes (Drag. 11 en particulier) au profit surtout de formes trapues très usitées (Drag. 29 [puis 37] et 30), plus commodes à fabriquer et transporter. L'usage des estampilles procède également des habitudes italiques. Mais le contenu de celles-ci pour l'essentiel (onomastique, formulaires, diversité des cartouches) diffère notablement des usages péninsulaires.

148. Des documents similaires sont attestés dans d'autres atcliers, surtout en France ; ils sont le plus souvent isolés et en maurais état.

149. Ce démarrage des ateliers à Ia Graufesenque, qui est archéologiquement sensible sous Claude grâce à l'extension quantitative et géographique de la diffusion des produits, correspond aussi à une transformation technique: l'apparition du vernis éblouissant, caractéristique de ce centre.

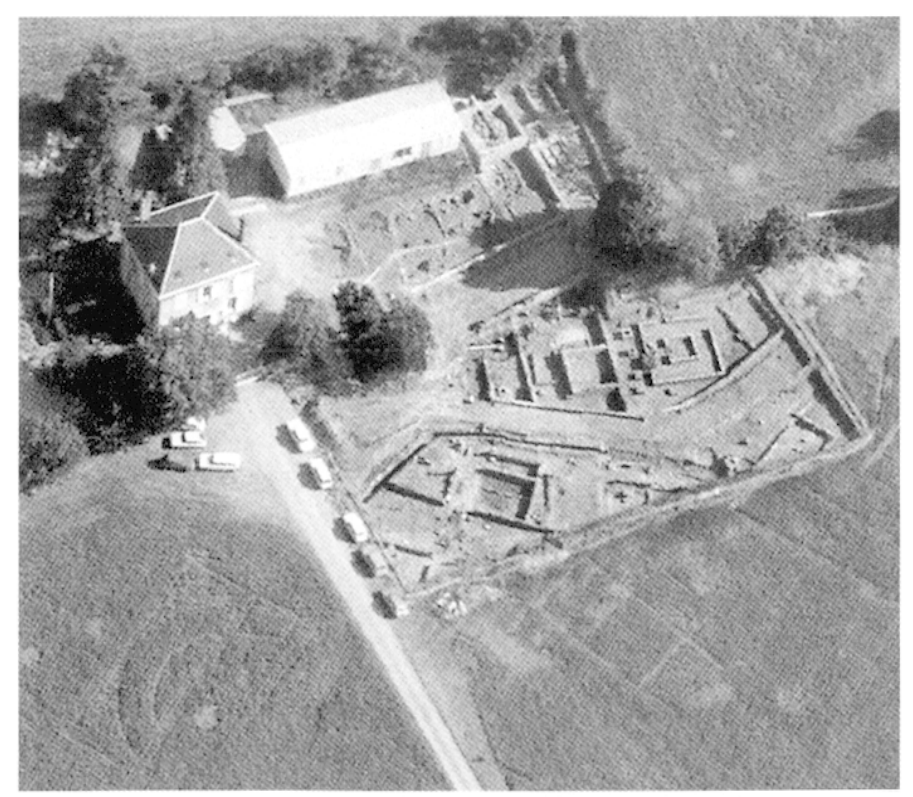

Fig. 56 - La Crraufesenque : vue aérienne des fouilles (photo archives du musée archéologique de Millau).

dans l'immédiat, de nouvelles considérations à ces débats. Le but de cette brève étude sera donc d'abord de proposer quelques remarques et suggestions à partir des documents ćpigraphiques qui sont entre nos mains.

\section{LES SIGNATURES DE POTIERS}

Ces marques premnent, à La Graufesenque comme ailleurs, deux formes : l'estampille et le graffite ${ }^{150}$. La première, la plus fréquente, la plus lisible (fig. 57), ressort le plus souvent en relief sur le vase et résulte de l'impression dans la pâte crue d'un sceau, gravé en creux en général de lettres majuscules (marques épigraphiques) ou de signes pseudo-épigraphiques (les "nébuleuses irréductibles" de F. Hermet) : assemblage inintelligible mais reconnaissable de hastes et de courbes ${ }^{1.51}$. Elle figure dans la très grande majorité des cas à l'intérieur de formes ouvertes, sur le fond, mais aussi, beaucoup plus rarement, sur la face extéricure de vases décorés moulés. Majoritairement inscrites en creux dans ou sous le décor, ces marques reproduisent alors en les inversant des caractères

150. I.es estampilles (ainsi que les graffites en capitales) seront, pour l'étude des marques, transcrites concentionnellement en capitales romaines, les graffites en ecriture cursive, reproduits en minuscules romaines, les groupes de lettres en ligature sont surlignés. Ia mention (r) signale une marque rétrograde, lisible de droite à gauche.

15l. Des poincons figurés servent également de marques dans différents centres (sud, contre et est de la (jaule). (e somt pour l'essentiel des rosettes. I.eur emploi régulier stur vases lisses parât limité, à Ia Gaufesenque, a certaines formes de rases (Vernhet, 1976. service F). Pour quelques exemples, sous des decors de moules, de rosettes, ou de marques pseudo-épigraphiques voir Mees, 1995, p. 180) (4) 181. Pour d'autres poingons figurés utilisés entre 90 et 150 voir Vernhet, 1991-1992, p. 56. 


\section{aरालM.0 \\ 1}

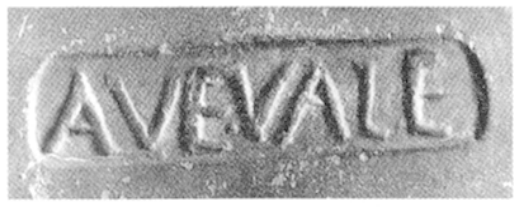

2

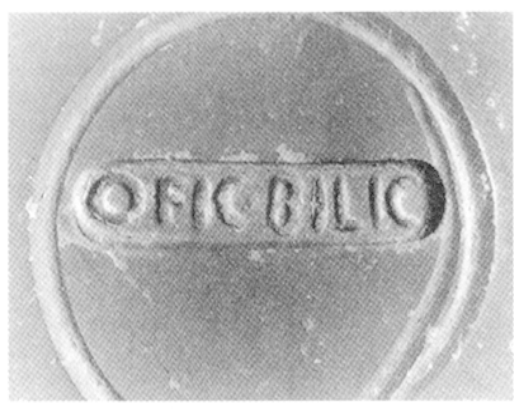

3

Fig. 57 - La Graufesenque, les estampilles : 1, poinson à estampilles, plaquette de terre cuite gravée en creux sur la tranche (OF.MASC.III 145-65]) ; 2, 3, signatures imprimées sur le fond intérieur de vases (AVE.VALE. ITiberel, OH(f)FIC(ina).BILIC(ati) [Tibère-Claude]) (d'après, Bémont et al., 1987, p. 23).

imprimés en relief dans le moule d'où est sorti le rase (fig. 65, MIIR(ATO).

Le graffite inscrit dans la pâte crue à l'aide d'un poinçon est la signature manuelle d'un artisan/ouvrier, dont il reproduit le nom, très souvent sous sa forme complète (fig. 62). Dans certains cas pourtant ce nom, très abrégé, ressemble plutôt à une sorte de griffe - AR(dacus), CAL(uinus), CIIN(sorinus), (;R(a...), N(...), etc. -, parfois difficile à développer. Les marques de ce type ctaicnt, à la Graufesenque, apposées à l'intéricur de moules décorés, le plus souvent sous le décor, parfois dedans. Les graffites inversés - en relief et le plus souvent lisibles de droite à gauche ${ }^{152}$ - sont, compte tenu de la minceur des traits, fréquemment peu visibles, voire partiellement effacés sur la paroi extérieure des vases. L'écriture est dans les cas les plus nombreux une cursive aisce ${ }^{153}$. Mais les potiers employaient parfois des capitales, par facilité, en particulier pour inscrire leur marque à l'envers sur le moule, afin apparemment de la rendre directement lisible sur les

152. I a lecture est parfois compliquée, quand la taille réduite du moule a oblige le seripteur a tracer son nom normakement de gauche à droite sous le décor. mais le bas des lettres tourné vers louserture de la matrice (Bémont, 1970) . Mees. 1995, pl. 20.6, 153.10, etc.).

153. Dans le cas de ductus heurtés il n'est pas toujours facile de distinguer une inscription à cru sur une pâte trop sèche d'une grature après cuisson (Bémont. 1972 : signatures signalées comme D[outeuses]).

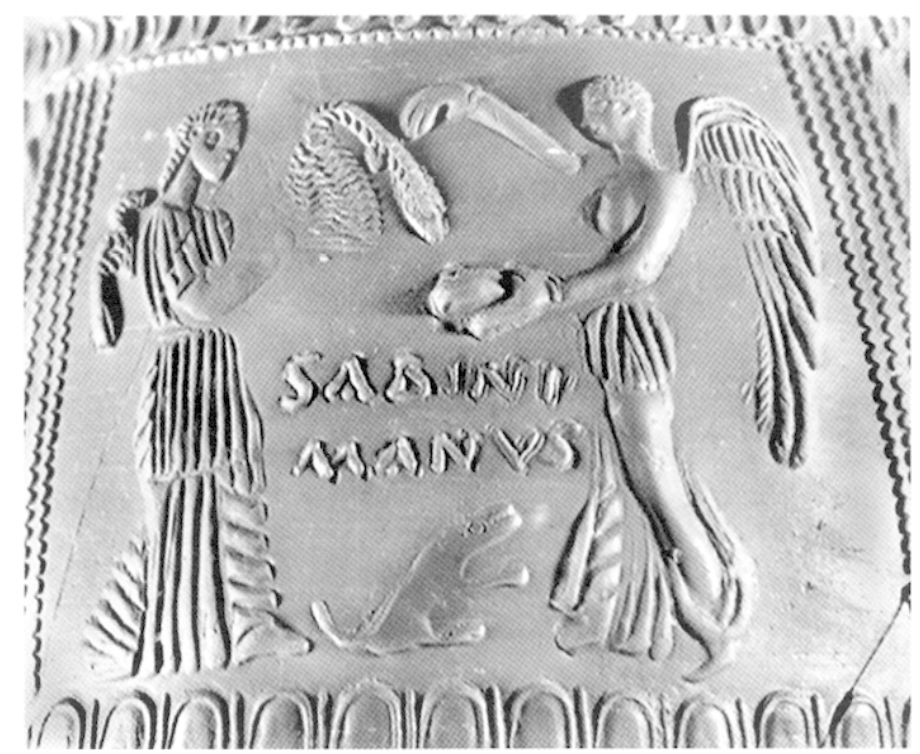

Fig. 58 - Grande layène signép en capitales SABINI MANVS (main! de Sabinus) dans le décor (rliché A. Vernhet, (NRS).

vases ${ }^{15.4}$. Cette intention est sensible sur une lagène de Sabinus, portant la mention SABINI / MANVS (fig. 58) au milieu d'un panneau décoré dans la partie supérieure du vase (Vernhet, 1979, pl. XXVIII).

\section{LES NOMS DE POTIERS}

Jusqu'à présent les marques à désinence nominale gauloise, en -os, sont exceptionnelles - RVTENOS FE(IT AR (retinum ?) et précoces (Vernhet, Hoffmann, 1992, p. 177-180). Les noms identifiables, d'après les nominatifs entièrement conservès sur vases ou moules, présentent en général ${ }^{15.5}$, quelle que soit leur origine, une désinence latine en -us (noms gaulois : Atepomarus, Bilicatus...) ou au moins, une terminaison en -o (diminutifs de type gaulois ?: Cotto, Mommo...) apparemment compatible avec une flexion latine (-o/onis). Il s'agit la plupart du temps de noms uniques, formés sur des racines latines, gauloises ou communes aux deux langues et au moins homonymes ${ }^{15 t}$. Ils sont considérés habituellement comme ceux de pérégrins.

\section{MARQUES Ȧ PLUSIELRS ÉLÉMENTS ONOMASTIQUES}

On observe toutefois des exceptions à ces usages, car certaines estampilles et de rares graffites comportent deux ou

154. Voir par exemple différentes signatures de Caluimus, Fuscus, Martialis, Masclus, Modestus, Sabinus, Secundus dans les planches de Mees, 1995.

15\%. Des noms latins nettement plus rares sont construits sur d'autres genres de thèmes : ainsi Macer et Viger (gen. Macri, Nigri), ou, dans la 3r déclinaison, Félix (gén. Felicis), Cénsor et Mermor (gén. Cimsoris. .Hemoris), Crescens et Pudens (gén. Crescentis, Pudentis). Semilis et lïtalis.

156. Des signatures diserses, peu fréquentes. comme lizis et ldmequis (origine $\vdots$ ), Protis (nom féminin gree $\vdots$ ), Semis, ou la formule latine Aue. Vale (salut. porte toi bien / adieu), ou encore le jeu de mot Salue / Saluetu / Saluetus (salue: porte-toi bien), n'ont con tout cas rien de typiquement gaulois. 
Tabl. X - Citoyenneté réelle et citoyenneté incertaine à La Craufesenque.

\begin{tabular}{|c|c|c|c|c|c|c|c|c|c|c|c|c|}
\hline \multicolumn{13}{|c|}{ Signatures avec gentilices : tria nomina, duo nomina (praenomen et nomen, nomen et cognomen) } \\
\hline Praenomen & Nomen & Cognomen & Date & Origine & Praenomen & Nomen & Date & Origine & Nomen & Cognomen & Date & Origine \\
\hline & & & & & Q. & Aemilius? & & $*$ & & & & \\
\hline C. & An( ) & Patr( ) & & & A. & An(n)ius? & & & & & & \\
\hline \multirow[t]{2}{*}{ G. } & At( ) & Pas( ) & & $* *$ & & & & & & & & \\
\hline & & & & & & & & & Aurelius & [I]ul( )? & Auguste & $* * * * *$ \\
\hline \multirow[t]{3}{*}{ C. } & $C()$ & $\mathrm{P}(\mathrm{)}$ & & $* * *$ & & & & & & & & \\
\hline & & & & & & & & & Cassius & $\operatorname{Cam}()$ & & $* * *$ \\
\hline & & & & & & & & & Cingius & Frontinus & & $* * *$ \\
\hline \multirow[t]{2}{*}{ C. } & Cinc/gius & Senouir & Trajan & & & & & & & & & \\
\hline & & & & & & & & & Cla(udius ?) & Gemma & Trajan & $* * *$ \\
\hline \multirow[t]{3}{*}{ L. } & Cosius & Virilis & Trajan & & L. & Cosius & Domitien-Trajan & & Cosius & Rufinus & Flaviens-Trajan & \\
\hline & & & & & & & & & Cosius & Vrappus & Néron-Vespasien & \\
\hline & & & & & L. & Fabius & & $*$ & & & & \\
\hline \multirow[t]{2}{*}{ T. } & $\mathrm{Fl}$ (auius) & Sec(undus) & Trajan & & & & & & Fl(auius) & Sabinus & Flaviens & \\
\hline & & & & & & & & & Fl(auius) & Germanus & Trajan & \\
\hline C. & lulius & Aemilius & & & C. & lulius & & & Iulius & Senis & & $* * *$ \\
\hline T. & Iulius & Aplas(tus) & & & & & & & & & & \\
\hline Q. & Iulius & Habitus & & & & & & & & & & \\
\hline Sex. & Iulius & lucundus & Vespasien & & & & & & & & & \\
\hline C. & Iulius & Primig( ) Surus & & & & & & & & & & \\
\hline C. & lulius & $\mathrm{Sa}()$ & & & & & & & & & & \\
\hline C. & Iulius & Seuerus & & & & & & & & & & \\
\hline \multirow[t]{2}{*}{ C. } & Iulius & Vassilius & Vespasien & & & & & & & & & \\
\hline & & & & & & & & & Orti(us) & Paullus & & $* * * *$ \\
\hline L. & $S()$ & Sabinus & & & & & & & & & & \\
\hline G. & Salarius & Aptus & Néron & & & & & & & & & \\
\hline C. & Siluius & Patri(cius) & & & C. & Siluius & & & & & & \\
\hline L. & Tertius & Secundus & Trajan & & & & & & Tertius & Masculus & Trajan & \\
\hline L. & T(ertius ?) & $\mathrm{S}($ ) & & $* * * *$ & & & & & & & & \\
\hline C. & Valerius & Albanus & Flaviens & & & & & & & & & \\
\hline Q. & V(alerius ?) & $C()$ & & $* * * *$ & & & & & Va(lerius?) & $\mathrm{Va}()$ & & \\
\hline
\end{tabular}

\begin{tabular}{|r|c|c|c|c|}
\hline \multicolumn{5}{|c|}{ Duo nomina apparemment sans gentilices } \\
\hline Praenomen & Nomen & Cognomen & Date & Origine \\
\hline Sex. & & Albanus & Claude-Vespasien & \\
\hline G. & & Albinus & Claude-Néron & \\
\hline A. & & Animus & Auguste & $* * * * *$ \\
\hline T. & (lulius ?) & Aplastus & & $* * *$ \\
\hline T. & & Audax & Auguste & \\
\hline M. & & Crestus/io & Flaviens & \\
\hline C? & & Fastus & & $* *$ \\
\hline L. & & Senis & Trajan & $*$ \\
\hline C. & & Silanus & & \\
\hline C. & & Siluanus & & \\
\hline L. & & Toc(ca) ? & & \\
\hline Sex. & & Varus & & \\
\hline
\end{tabular}

\begin{tabular}{|ll|}
\hline$*$ & Vernhet, 1991 \\
$*^{* *}$ & Mees, 1995 \\
$*_{* * *}^{* * *}$ & Bourgeois, 1995 \\
${ }_{* * * * *}$ & Hartley, 2002 \\
italique & Génin, Hoffmann, Vernhet, 2002 \\
\hline
\end{tabular}


plusicurs éléments onomastiques diversement explicables et dont on peut tirer des indications sur quelques statuts sociaux ou professionnels. D'abord on note, à partir de la seconde moitié du $\mathrm{I}^{\mathrm{er}}$ s., l'emploi, selon le schéma romain, de tria nomina ${ }^{157}$, signe habituel de l'affranchissement pour l'esclave ou de l'acquisition pour un étranger du droit de cité (fig. 64). La proportion en est très faible sur au moins $400 / 450$ potiers signataires attribués à La Graufesenque ${ }^{158}$. Le tableau X, établi à titre indicatif ${ }^{159}$ à partir des listes publiées d'après les relevés de A. Vernhet (Bémont, Jacob dir., 1986, Annexe, p. 278-286) et d'informations ultérieures, montre, d'une part, le petit nombre des gentilices concernés, d'autre part, le respect approximatif des usages romains classiques (omissions de cognomina ${ }^{160}$, de praenomina). On peut noter en outre que, dans le cadre étroit du cartouche des estampilles, nomen et cognomen font fréquemment l'objet d'abréviations et que le gentilice, comme une sorte de préfixe, est souvent très réduit: OF L.C.VIRILI, OF $\overline{F L}$ A.SAB, OF T.F.SE, C.IVL.CLE, T.IVL.PR.SVR, C.I.SA, L.T.S., Q.V.C. Il ne semble donc pas que la citoyenneté romaine dans les ateliers de La Graufesenque soit très ostentatoire. Ce qui permet de douter que les marques de potiers soient un indicateur fiable de son extension ${ }^{161}$, surtout si l'on inclut parmi ces fantaisies des combinaisons rares de praenomina et de cognomina sans savoir (sauf pour Aplasius) si des noms complets, avec gentilices, ont jamais existé.

D'autres échantillons sont composés de différents éléments onomastiques, le plus souvent deux, abrégés et dont les relations posent souvent un problème. Il s'agit d'un phénomène précoce puisque les plus anciens échantillons comportent deux lignes à la manière des marques de potiers italiques qui ont influencé les débuts de La Graufesenque. Étudiées récemment par B. R. Hartley (2002), ces estampilles ont été classées en trois groupes ${ }^{162}$ en fonction de leurs caractères morphologiques: nombre de lignes, importance des abréviations qui affectent également les éléments, ou surtout l'un d'eux. L'analyse attentive des signatures a montré à l'auteur, pour la plupart des échantillons, l'impossibilité d'y reconnaître

157. Oswald, 1931, les tenait le plus souvent comme résultant de l'association de deux potiers. On note, il est vrai, l'usage synchrone de noms uniques identiques à certains des cognomina. Mais on tend actuellement à attribuer ces dernicrs aux officines utilisant les tria nomina.

158. Selon A. Vernhet. Le total atteindrait au moins 500 potiers d'après les attributions de Leeds (Dannell, 2002, p. 220).

159. D'après Hartlcy, 2002, p. 134, n. 1, l'Index inédit des marques de poticrs de Leeds nc pcrmet pas d'accroittc considérablement le nombre des exemples, qu'il porte à une cinquantaine.

160. Cette pratique caractérise aussi la Firmastempel italique utilisée entre le milieu du $\mathrm{I}^{\mathrm{er}} \mathrm{s}$. av. J.-C. et le cours du $\mathrm{I}^{\mathrm{cr}} \mathrm{s}$. de notre ère. Mais a-t-elle en Gaule la signification qu'on lui prête en Italie: usage commun de la marque indifférenciée du patron couvrant globalement les ouvriers de son entreprise?

161. Le choix délibéré comme marque du simple cognomen par un potier citoven ou affranchi a été observé dans des ateliers italiques (Bémont, 1991, p. 138) ; il paraît donc a fortiori possible dans un milieu d'hommes libres gaulois, où le nom unique constituait l'usage normal.

162. A: marques sur deux lignes ( 9 combinaisons) ; $B$ : noms très abrégés ( 17 combinaisons dont 16 nouvelles); $C$ : deuxième élément très abrégé (33 combinaisons dont au moins 6 douteuses). des tria nomina tronqués. Si pour un grand nombre d'entre elles l'hypothèse de marques de potiers associés est soutenable ${ }^{163}$, l'identité des contractants est loin d'être toujours assurée et les structures des sociétés demeurent imprécises.

\section{MARQUES $\Lambda$ UN SEUL ÉLÉMENT ONOMASTIQUE}

Les noms composés d'un seul élément et estampillés ont fait aussi l'objet de différents traitements graphiques, apparemment pour en abréger la longueur et la rendre compatible avec les petits cartouches oblongs, très fréquents à La Graufesenque, même si la taille du support ne l'exigeait pas. Plusieurs méthodes concourent à ce résultat. Et des marques de formes très variables sont le plus souvent utilisées dans les mêmes officines.

Le nom peut être employé seul au nominatif ou au génitif. Mais, de la façon la plus simple, la fin du mot peut être abrégée par la suppression du S final au nominatif - ACVTV(s), GEMINV(s) - Il est difficile alors d'invoquer une raison phonétique dans la mesure où le même atelier use concurremment de marques avec ou sans $\mathrm{S}$. La désinence plus ou moins complète du nominatif - F CALV(us) - ou du génitif - $O$ ARDAC(i), OF FIRMON(is), OFI .FIRMO(nis) - peut disparaître, ou encore la dernière syllabe du nom - OF ARDA(ci), CABVCA(tus), MERCA(tor), VITA(lis) -, voire plus - OFI BILIC(ati), CABV(catus), LEP(idus), MO(mmonis) $\overline{\mathrm{MA}}$ (nu) -. Ces apocopes suscitent d'ailleurs des hésitations pour l'attribution de certaines marques très abrégées à des noms différemment suffixés (par exemple, Firmo et Firmus). Les doubles lettres font également les frais de telles économies - MOM(m)O, O PAS(s)IEN(i) -. Enfin les ligatures, fréquentes mais le plus souvent limitées à deux - $\overline{\mathrm{AV}} \mathrm{E}, \operatorname{IVCV} \overline{N D V}(\mathrm{~s})$ - ou trois - OF $\overline{\mathrm{AIE}} \mathrm{OO}(\mathrm{)}$, OFIC $[\overline{\mathrm{ANI} I}$ - lettres contiguës, donnent à quelques graveurs l'occasion d'exercer leur virtuosité. À titre de curiosité une toute petite estampille: DONS (Bémont, 1976, n' 146) doit être développée en DONATVS.

Une particularité toutefois semble singulariser La Graufesenque : la propension des graveurs de poinçons à supprimer les I en contact avec des lettres à hastes (fig. 59). Des ligatures sont parfois normalement marquées par le dépassement duI au-dessus de la haste voisine - OF CASTI, OF FIRMO(nis) -, voire par la verticalité d'une haste normalement oblique - $\overrightarrow{\mathrm{VERIV}}$ (gus) -. Mais il advient souvent que le I disparaisse totalement et sans qu'aucune raison phonétique puisse être invoquée: NGEN(uus) = INGEN(uus), OF NGR(i) $=$ OF $\overline{N I G R I}$, PASSENI MA = PASSIENI MA, OF PRM = OF PR $\overline{I M}(i)$ ou PR $\overline{I M I}$ ? Compte tenu de ces habitudes, il sera difficile de distinguer ligature "invisible " et apocope quand on attend un I final. Il est visible en tout cas que certains amateurs, rares mais doués, se sont amusés à combiner plusieurs ligatures ou plusieurs modes d'abréviation: QVINT $\overline{\mathrm{ANI}}, \overline{\mathrm{MV}} \mathrm{R}(\mathrm{r}) \mathrm{ANI}$, $\overline{\mathrm{MVR}}(\mathrm{r}) \overline{\mathrm{ANVS}} \mathrm{F}, \overline{\mathrm{MV}} \mathrm{R}(\mathrm{r}) \overline{\mathrm{AN}}$ ou $\overline{\mathrm{ANI}}$, ? O PAS(s) $\overline{\mathrm{EN}}=\operatorname{PAS}(\mathrm{s}) \overline{\mathrm{IEN}}$

163. Hartley, 2002, p. 134, 137 et 138, souligne toutefois, parmi ces exemples, le problème posé par un groupe de noms (ARDACI, CAPITO, FELICIO, LICINI, LVCCEI, MARTIALIS) identiquement suivis par le monogramme $\overline{V A}$ dont l'interprétation (= MA, VA(scularius), nom abrégé $\vdots$ ) est loin d'être assurée. 


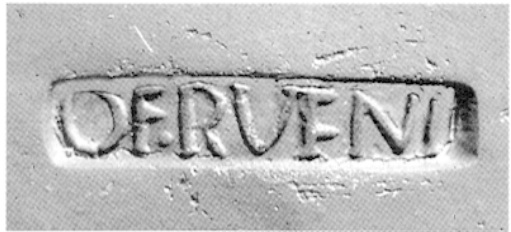

Fig. 59 - Signature de Rufinus à ligature invisible : OF(ficina).RVFINI (cliché A. Vernhet, CNRS).

ou IENI. Ce jeu prouve au moins che\% ces artisans une certaine maitrise dans le maniement de la gravure et de l'orthographe.

\section{LES ÉLEMENTS FORMULAIRES}

Tous latins à La Graufesenque, ils accompagnent fréquemment le nom du potier et présentent trois formes principales, attestées souvent concurremment avec les mêmes noms, en Gaule du Sud et en Gaule du Centre ${ }^{161}$ : officina + génitif, manu + génitif, fecit + nominatif. En quoi ces éléments lexicographiques (souvent abrégés pour gagner de la place) ${ }^{165}$ nous renseignentils sur la structure des ateliers et le statut des potiers?

Comme je l'ai signalé ailleurs (Bémont, 1991, p. 142), il est logique de penser que manu ( "de la main de") a pu impliquer une participation personnelle à la fabrication, et de supposer, en revanche, qu' officina ("dc ? l'officine de » ou " officine de ») renvoic globalement à l'atelier identifié par le nom du patron. Fecit conserve une certaine ambiguité, du moins dans un contexte latin, car ce verbe, tout en impliquant la responsabilité du signataire, signifiait aussi bien "faire faire " que "faire ". Ainsi fecit, employé exclusivement dans un centre de production (comme il advient en général dans l'est de la Gaule), pourrait dans certains cas ${ }^{16 i i}$, aussi bien qu'officina, renvoyer en fait à un patron d'atelier. La multiplicité des libellés associés au même nom propre, comme à La Graufesenque, est difficile à interpréter. Comme référence est faite dans tous les cas à un seul et même potier, tout au plus peut-on imaginer sur ces bases les rapports plus ou moins directs du signataire avec l'objet signé ${ }^{167}$. Mais on ignore, faute d'informations extérieures sur la coutume ouvrière, si les différentes formules n'ont qu'un sens

164. Lissage peut êre sélectif ailleurs: ainsi la formule officina, inconnue dans les ateliers de l'est, est seule employée en Espagne (EX OFFI(INA).

165. OFIC, OFI, OF e () sont frequents, les deux derniers avant on après le nom. Dans ce cas, la lecture peut soulever un problème (CRESTIO $=$ (irestio ou (iresti O(ffirina) . FEC, FE ou $\mathrm{F}$ remplacent souvent fecit avant ou après le nom. Outre les abréviations, Manu se prête par la forme des lettres à diverses ligatures. Les solutions les plus simples: $\mathrm{M}$ ou $\overline{\mathrm{MA}}$, somt les plus cmployées, mais on rencontre aussi $\overline{\mathrm{MAN}}$ voire $\overline{\mathrm{MANV}}$.

166. Une hypothétique délégation est toutefois plus raisonnablement concerable dans le as d'unc estampille que dans celui d'une inscription manuscrite.

167. À moins de conventions professionnelles inconnues de nous, l'emploi d'un sceau admet virtuellement la délégation de toute estampille, même de type " $X$ mamu ". Mais cette observation est de peu de portée, car cette formule est de loin la plus rare parmi les estampilles de La Gaufesenque. banal ou relèvent d'un code professionnel. Aussi ne sait-on pas, en l'absence de datations très fines de l'emploi des différentes estampilles, si deux ou trois libellés étaient utilisés en même temps, selon les besoins, par un fabricant, ou s'ils ne correspondent pas plutôt à l'évolution de la situation de ce dernier, d'ahord au service d'une entreprise avant qu'il ne devienne patron (officinator) ${ }^{16 i}$. À moins encore que ces modifications ne révèlent les changements du statut d'un potier responsable et la transformation simultanée de son atelier-officina désignant par exemple une entreprise d'une certaine importance (Polak, 1989), par opposition à une échoppe d'artisan.

Nous ne disposons pas actuellement, en tout cas, de moyens pour déterminer à La Graufesenque, grâce à des observations archéologiques ou des traditions textuelles de portée locale, la signification exacte d'officina (et officinator) par rapport à la propriété du sol ${ }^{169}$. Pour parler d'exemples relativement proches, on sait bien que la fabrication des briques en Italie, au II" s., mettait explicitement en cause, dans les sceaux imprimés sur les produits, les compétences respectives des domini, propriétaires des domaines fonciers (praedia) et des glaisières qui s'y trouvaient, et des officinatores, préposés à la production des céramiques à partir de cette argile. Et l'on discute depuis longtemps de leurs responsabilités respectives dans la fourniture des produits finis et des liens contractuels qui pouvaient régler leurs rapports. Par ailleurs, la question de l'existence de structures comparables a été largement envisagée et débattue pour d'autres produits, à propos en particulier des amphores de Bétique (Bémont, 1991, p. 140-142).

Mais aucun document, pour le moment, ne permet concrètement de présumer de la qualité des propriétaires du sol sur le tcrritoire de Condatomagus au $\mathrm{I}^{\mathrm{rr}} \mathrm{s}$. (Dannell, 2002, p. 211-215, 220 et 236-238), ni des rapports plus ou moins contraignants qu'ils auraient pu entretenir avec la multitude des officinae attestées sur le site ${ }^{170}$. On ne connaît pas davantage d'après les fouilles l'importance des locaux (essentiellement des hangars) et du personnel dont pouvait disposer un officinator. Ces notions supposent certes une compétence technique, donc une responsabilité, mais nous ignorons si le concept d'officina en ce licu, à cette époque, impliquait d'abord un statut « juridique » et, dans cette hypothèse, s'il était lié à une délégation de pouvoir, une mission confiée à son directeur, ou si l'emploi de ce terme reflétait simplement l'importance relative atteinte par certains

168. Voir du moins par analogic, à I.c\%oux, les questions soulevées par Thomonymic de signataires de moules (décorateurs) et de patrons d'officines, tenus pour globalement synchrones, mais employant des répertoires iconographiques totalement ou partiellement différents (voir par exemple Bémont, 1994, Aunus et (atussa, p. 43 et 44). Sagissaitil du même individu évoluant dans la hiérarchie professionnelle?

169. Voir les hypothèses émises à propos de la Graufesenque sur les structures de la production par K. Strobel et ses émules (par exemple Fülle, 2000) a partir de papyri d'oxyrhinque, concernant des travaux exécutés par des potiers liés par des contrats temporaires à des proprićtaires fonciers ou bailleurs de fonds. Comparer avec les positions très critiques de Jacob (198la et b) e Jacob, l.eredde, 1986 (ateliers = lieux de " non-droit") ou plus modérées de Dannell, 2002.

170. Selon Damnell, 2002, p. 220, 215 pourraient être prises en compte et réparties sur toute la durée de la production des sigillées sur le site (Auguste-milicu du II"s.). 
ateliers. Comment évaluer cette importance ? En juger d'après la fréquence des produits signés, ou le nombre des estampilles différentes, permet de dire que certains potiers étaient plus diffusés que d'autres, sans que l'on sache vraiment, compte tenu des datations actuellement publiées, si ce phénomène était lié plutôt à l'importance des entreprises qu'à la durée, aléatoire, de leur fonctionnement, ou de leur représentation locale ${ }^{171}$. Par ailleurs, supposer comme K. Strobel que chaque officina disposait par principe d'un four relève de la gratuité, faute, à La Graufesenque, de preuves en nombre sur le terrain, et soulève aussi quelques problèmes. Dans le cas du grand four découvert en 1978 , daté entre 80 et 120 , et dont le volume interne est évalué à environ $80 \mathrm{~m}^{3}$ cette proposition paraît totalement irréaliste ${ }^{172}$. Mais prendre en compte toute petite installation, éventuellement sans tubulures ${ }^{173}$, comme les deux structures rondes à sole, bâties en enfilade (fig. 60) au nord-est du grand four ${ }^{17-4}$ et contemporaines de celui-ci, ne contribuerait qu'à souligner les disparates entre des entreprises supposées importantes et productrices de sigillée et par conséquent à infirmer la portée de cette caractéristique.

\section{ESTAMPILLES ET GRAFFITES : LEURS RÔLES RESPECTIFS}

\section{LES ESTAMPILLES}

Les estampilles peuvent être utilisées à deux stades de la production : sur les vases lisses ou décorés, dans les moules destinés à la production des vases ornés. Les unes correspondent à l'impression par un ouvrier ${ }^{175}$, sur un vase cru (en général à l'intérieur, au centre du fond), d'un sceau gravé portant, le plus souvent, un nom. Fréquente à La Graufesenque ${ }^{176}$ au I $\mathrm{I}^{\mathrm{k1}}$ s., cette pratique n'ètait pourtant pas systematique. Rien en tout cas ne permet de déterminer sûrement l'identité de ce tourneur de base (signataire responsable de l'atelier, ou anonyme: simple employé, ou sous-traitant ?), et encore moins de préciser son rapport ou, éventucllement, celui de son employeur avec un graveur (présumé spécialisé? et alphabétisé) du sceau. Quoi qu'il en soit les signatures de type officina suggèrent plus que d'autres la possibilité d'une identité

171. Il faudrait en effet pondérer ces observations, étant donné le caractère souvent très inégal de la répartition des marques dateliers contemporains seton les microrégions consommatrices intéressées.

172. On doit tenir compte, dans ce cas, à la fois de la taille impressionnante du bâtiment et du nombre des potiers signataires concurremment attestés dans ses ruines. Voir, de même, les six potiers signataires (à officina) trouvés ensemble dans les surcuits de la fosse dite de (ïrratus (Dannell, 2002, p. 220).

173. Ces aménagements internes permettaient de cuire les vases sigillés, empilés sur des étagères, à l'abri des gaz de combustion, et d’assurer la régularité de leur qualité.

174. On n'a d'ailleurs retrouvé arec ces fours (environ $90 \mathrm{~cm}$ de diamètre) que des petits gobelets à parois fines, totalement anonsmes.

175. Il paraît implicitement admis, en labsence de preuves d'un partage du travail, qu'il s'agit du tourneur du vase.

176. Dans une fosse remplie de rebuts entre 55 e 60 la plupart des quelque 9000 rases étaient estampillés (Bémont, 1987).

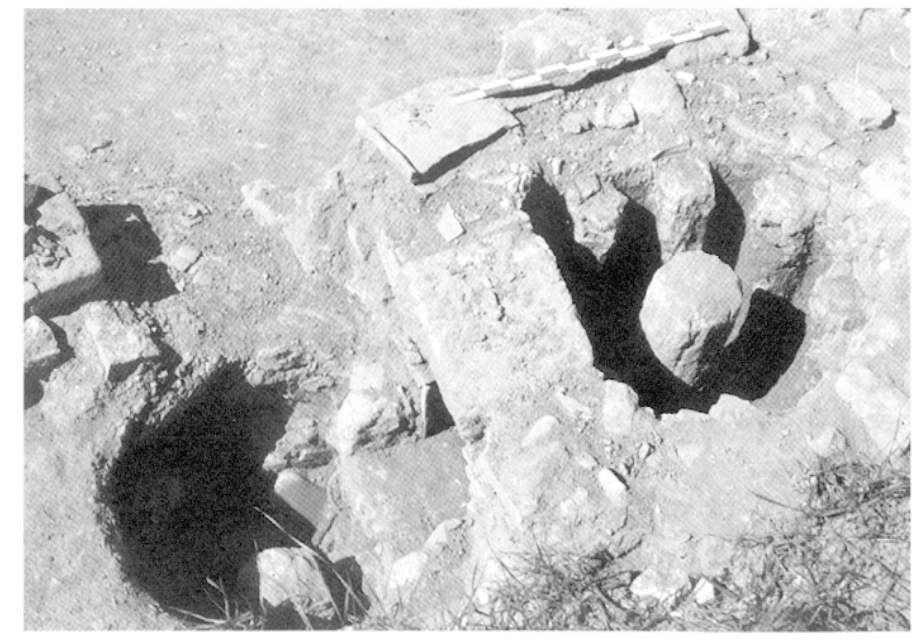

Fig. 60 - La Graufesenque : les deux petits fours (diamètre de chacun : $90 \mathrm{~cm}$ ) en enfilade et en escalier; découverts au nord-est du grand (cliché A. Vernhet, CNRS).

partagée et d'un anonymat individuel (l'emploi du nom scul, à mon avis, ne permettant vaiment de préjuger de rien ${ }^{17 i}$ ). Il est évident que ce genre de marque, intervenant au moment du tournage du vase, n’intéresse que cette opération. Et on est fondé à douter, particulièrement dans le cas de la vaisselle non décorée, que ces signatures aient eu une fonction publicitaire : la remarquable normalisation des formes, des tailles, de la pâte rendait interchangeables les vases des différents ateliers aussi bien à l'intérieur de fours collectifs où ils étaient cuits (Bémont, 1987 et infra, p. 119, 122 et 128, et fig. 70) que sur la table des consommatcurs. Parallèlement l'usage du sceau imprimé à l'intérieur des moules destinés à la fabrication de vases décorés est lić matériellement à la fabrication de ces matrices, mais sa place et son contenu incitent cependant à s'interroger sur le rôle du signataire dans le déroulement des opérations menant de l'impression des poinçons iconographiques dans le moule cru jusqu’à l'achèvement de vases moulés.

\section{LES GRAFFITES}

Inscrits à l'intérieur des moules ${ }^{17 \pi}$, sous ou dans le décor, ils sont au contraire plus spontanément atuibués à un acteur : le

177. Contrairement à l'hypothèse de M. Polak (1989, p. 150) : nominatif seul $=X$ ferit, génitif $=$ officina ou mamu de $X$. Supposer une telle coherence grammaticale dans l'usage de ces formules elliptiques ne permet pas de trancher formellement entre officina et manu, donc de différencier à coup sûr le sens général du nominatif de celui du génitif. Peut-on démontrer, par ailleurs, que tous ces contenus étaient rigoureuscment codés et quaucun phénomène aléatoire, par exemple de mode, n'a influence le choix des potiers.

178. Mees, 1995, p. 184. signale 9 poincons iconographiques (destines a la decoration des moules) portant une signature inscrite. Vernhet. 1991-1992. p. 53. en mentionne 5 de plus (signés par Arutus, Fïmus, I.upus, Pontus. Volturius). Tous portent le nom de potiers comnus, plus ou moins célèbres. Il n a pas été prouvé que les outils étaient ststématiquement employes par leurs auteurs/proprictaires et la documentation est trop réduite pour que lon puisse montrer des relations significatives aree derentuels clients. 


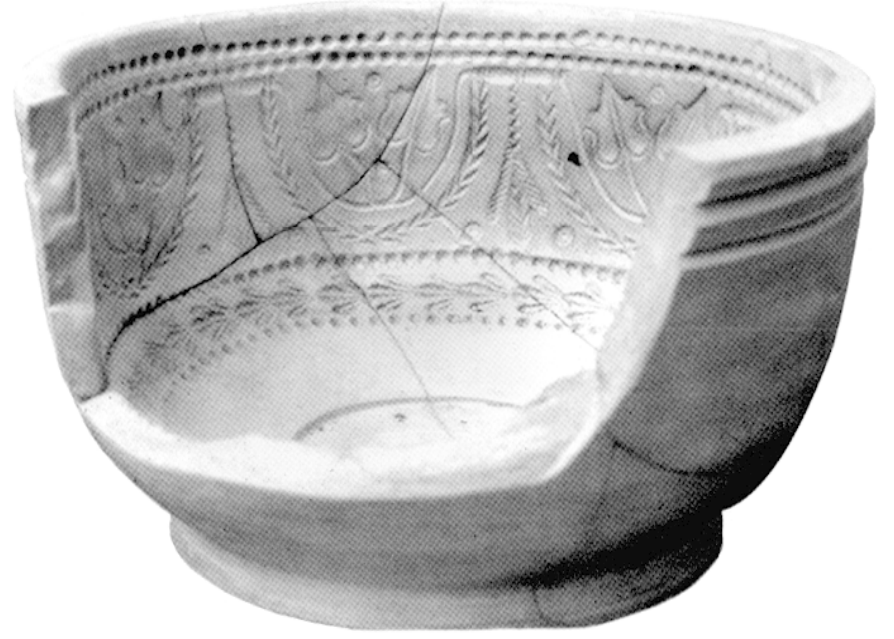

Fig. 61 - La Graufesenque, fosse de Gallicanus : exemple de moule à décor imprimé à l'aide de poincons (gobelet de type Her. 9) (cliché C. Bémont, CNRS).

fabricant/décorateur qui réalise la frise ornée ${ }^{179}$ (fig. 61). Ce sentiment est renforcé par le fait que cette signature comporte, en règle générale, un nom, abrégé ou non, seul ou accompagné des mentions manu(s) ou fecit et par les similitudes observées entre les contenus de décors pareillement signés. La mention officina semble en revanche exceptionnelle dans ces suscriptions ${ }^{180}$. Cela admis, restent les questions posées par la coexistence sur les mêmes pièces de plusieurs signatures - le plus souvent une estampille et un graffite. Les observations sur de tels échantillons n'ont évidemment qu'une portée limitée, compte tenu de la faible proportion des vases moulés décorés par rapport aux dizaines de milliers de vaisselles lisses. Fncore faut-il distinguer les usages selon les types signés ${ }^{181}$.

\section{LE CAS DES FORMES DÉCORÉES}

\section{Les bols carénés Drag. 29}

Produits entre Tibère et le cours du règne de Domitien, ils portent souvent, à l'intérieur, l'estampille du fabricant de vases, à l'extérieur sur la face ornée, la signature du producteur de moules reproduite en même temps que le décor (fig. 62). Si la majorité de ces marques extérieures consistent en graffites, plusieurs séries de pièces ornées portent cependant une estampille dans le décor. La majorité de ces sceaux ${ }^{182}$, enfermés dans

179. Je néglige ici la question anecdotique soulevéc par des graffites sûrement ou probablement inscrits sur moules après cuisson (voir supra, n. 153, p. 105) et qui supposent soit l'oubli d'un fabricant signataire, soit une réappropriation du moule.

180. Mees, 1995, p. 167, ne cite que des exemples dus au poticr Mommo et figurant à l'intérieur des frises décoratives.

181. J'utilise comme base, par commodité et à titre indicatif, les recensions de Mees, 1995 (94 potiers ou styles), confrontées à la liste des 96 signataires publiée dans Vernhet, 1991-1992, p. 54-56.

182. Quelques marques plus grosses, en creux et rétrogrades dans le moule, échappent à ces remarques: M.CRESTIO, IVST (voir fig. 65, L.COSI).

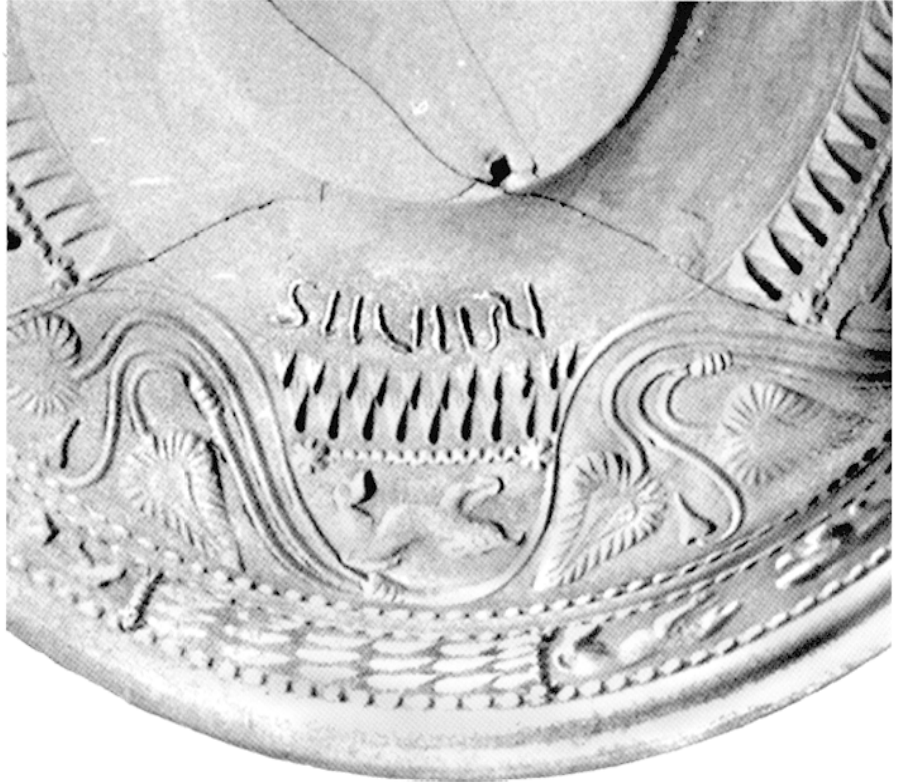

Fig. 62 - La (rraufesenque : moule de bol Drag. 29 signé du graffite infradécoratif Siuuiri (de Seuerus [Néron-Vespasien])

(cliché A. Vernhet, CNRS).

un étroit cartouche, étaient imprimés en relief dans le décor des moules à l'aide de poinçons semblables ou identiques aux sceaux utilisés sur le fond des vases (bols carénés ou vaisselles lisses). Reproduits en creux et inversés dans la frise ornée des bols, leur double moulage tend à réduire leur lisibilité. Leur usage professionnel (propriété des moules?) paraît donc en général beaucoup plus vraisemblable que leur impact publicitaire.

Certains potiers semblent revendiquer toutes les étapes de la fabrication. Ainsi on connaît de Murranus (50-65) des bols signés intérieurement de l'estampille OF MVRRA ou -AN, extérieurement de graffites rétrogrades sous le décor (Muran/ Murani) ${ }^{18: 3}$, dans un cas même à la fois d'un graffite infradécoratif - Murani ( $r$ ) - et d'une estampille rétrograde intradécorative - OF MVRRAN - (Mees, 1995, 153.10). D'autres échantillons de cet atelier ne portent que les deux signatures extérieures. Mais l'état de conservation du mobilier ne permet pas d'assurer que l'usage de la triple signature n'était pas plus fréquent. D'autres signataires de moules ont partagé, objectivement, l'usage de leurs matrices avec des fabricants de bols: ainsi Gallicanus (50 ?-65) avec Patririus et Senicio ${ }^{184}$, Modestus (50-70) avec Aper, Crostio et Felix ${ }^{185}$, Mommo (70-90) avec Manduilus ${ }^{186}$ et sans doute Niger (Mees, 1995, 145.11). Il paraît évident que les moules utilisés, pour une part, par leurs fabricants, sont aussi passés dans les mains d'autres producteurs de vases, mais on

183. Voir également Ardacus, Frontinus, Martialis, Masclus, Mefillus, Pontus, Vitalis.

184. OF GAI.IC: (r) dans le décor; OF PATRICI ou SENIC iI ) FEC dans le vase.

185. Mod (r) sous le décor ; OF APRI, OF (RESTIO), OF FELICIS dans le vase.

186. Mom (r) sous le décor: MANDVII. MA dans le vase. Voir également Acutus et Bassus, Iustus et Iucundus, Passienus et Aeuus. 
ignore les conditions exactes - commerce d'outils, récupération de matériel a posteriori - dans lesquelles ces partages se sont effectués ${ }^{187}$.

Quelques décorateurs, en revanche, semblent entretenir des relations privilégiées avec un producteur de vases : c'est le cas, d'après plusieurs pièces marquées, d'un anonyme utilisant une marque pseudo-épigraphique intradécorative et du potier Vanderio (Mees, 1995, p. 180). Il est cependant difficile d'imaginer, d'après les seules signatures, l'extension de ces pratiques, compte tenu du nombre des couples qui ne sont actuellement signalés qu'à un exemplaire, et de définir les relations qu'elles impliquent (association, dépendance ?). Il est possible, en revanche, de signaler les probables rapports de dépendance ou de sous-traitance qu'entretenaient certains potiers signataires intéressés ensemble à la production d'un moule. Par exemple, la marque GALLICANI se retrouve au fond d'un vase portant à la fois dans le décor l'estampille OF GALIC (r) et, sous le décor, la modeste griffe manuscrite N.fe.

Notons encore que certains 'tourneurs de vases ont utilisé les matrices de différents poticrs : c'est le cas d'Aper, fourni par Modestus et Lupus, ou de Patricius alimenté par Murranus, Caluus et Gallicanus. Plusieurs potiers, dans l'état de notre information, sont connus comme fournisseurs de quelques moules Drag. $29^{188}$, mais le reste de leur production échappe à l'analyse ${ }^{189}$. D'autres, enfin, ont cumulé les fonctions de fournisseurs de moules et d'utilisateurs de moules étrangers : un bol de Carillus sort d'un moule de Crestio, qui a utilisé, en revanche, une matrice de Modestus; Senicio signe un vase dont le décor porte la marque intradécorative OF GALIC ( $r$ ), mais a fourni un moule à Celadus. Les exemples connus sont encore trop rares pour que l'on puisse savoir s'il s'agit de phénomènes accidentels, d'une évolution diachronique dans le statut professionnel des potiers concernés, ou encore d'une collaboration informelle entre producteurs polyvalents. Ces différents aspects du partage des fonctions jettent en tout cas de sérieux soupçons sur la pertinence de l'identification de styles iconographiques (voir les travaux de R. Knorr), d'après les seules signatures imprimées à l'intérieur des vases ornés.

La présence, assez fréquente, à l'extérieur des bols Drag. 29 ou dans les moules, de signatures isolées de nature variable - graffites, le plus souvent sous le décor, parfois dans le décor ${ }^{190}$, ou estampilles dans le décor -, ne justifie pas, par simple analogie, des hypothèses fondées concernant les utilisa-

187. Les graffites de Gallicanus, Modestus, Mommo, etc. sont, concurremment, associés sur des bols aux signatures intérieures mentionnant les officinae de ces producteurs. Et la datation des vases est, en général, insuffisamment précise pour que l'on puisse déterminer dans chaque cas un décalage chronologique entre les différents usagers des matrices et une situation temporaire de dépendance dans la carrière du fabricant de moule.

188. Albinus (Peregrinus), Caluus (Patricius), Crestio (Carillus), Iupus (Aper), Mas... (Primus, ...nus, illisible), Sabinus (Homobomus), Volus (Licinus).

189. Certains de leurs Drag. 29 sont trop mutilés (Albinus, Mas(), Volus). Et les échantillons dont nous avons disposés par ailleurs appartiennent à des formes normalement sans marques intérieures (Drag. 30, 37 , etc.).

190. Albini, Calus f, Mo(destus), Secundinim, Secundim. teurs (fabricants eux-mêmes, ou " clients" ?) des moules en cause : on dispose le plus souvent d'échantillons mutilés, trop peu nombreux, très inégalement répartis entre les ateliers et dont le caractère représentatif semble éminemment contestable. On peut observer toutefois que les estampilles, relativement rares et toujours intradécoratives, ont des contenus très variables ${ }^{191}$ qui ne permettent actuellement de préjuger ni de leur spécificité, ni, pour les potiers intéressés, d'une fonction particulière dans la fabrication du moule. La nature même de ces signatures (indépendamment du libellé) implique sans doute la possibilité matérielle d'une délégation du travail, mais rien n'en prouve l'usage régulier, ni même fréquent ${ }^{192}$. Enfin, si leur utilisation paraît plus importante (comme celle des marques en général) à partir du milieu du $\mathrm{I}^{\mathrm{cr}} \mathrm{s}$., on ne semble pas avoir montré qu'elles correspondaient systématiquement à des pratiques tardives dans leurs ateliers respectifs.

\section{Les autres formes décorées}

Leur situation est plus simple, dans la mesure où les signatures de tourneurs de vases sont alors inusitées. Les vases de fantaisie sont en général peu représentés. Ia recension de Mees, 1995 (voir supra, n. 181, p. 110), complétée à l'aide de la liste de noms et formes publiée par A. Vernhet (1991), atteste une trentaine d'échantil- lons datés par les potiers et la duréc des types ${ }^{193}$ (fig. 63) : quatre calices Drag. 1 la (20-au moins $50)$, six ou sept lagènes (50-70), huit gourdes Déch. 63 (70-100/110), quatre gobelets ovoïdes Déch. 67 (au moins dernier quart du $\mathrm{I}^{\mathrm{ar}}$ s.), six petits bols Knorr 78 (70-90/95). Tous signés dans le décor, ils portent tantôt des estampilles le plus souvent directes ${ }^{194}$, tantôt des graffites ${ }^{195}$. Le nombre de ces pièces, même s'il n'est qu'approximatif, est trop faible pour que l'on puisse tirer des conclusions de leurs particularités épigraphiques.

La forme des bols Drag. 30 (Tibère-100/110) : un cylindre profond, décoré et mouluré jusqu'à l'attache du fond (fig. 63), interdit pratiquement dans le moule les signatures infradécoratives, et les graffites inscrits sur le fond paraissent très rares à La Graufesenque ${ }^{196}$, d'autant plus que, effacés sous les vases

191. FORMA OPIANI (Tibère), ACVTIM (20-45), VOI.VS (20-50) ; AVRELIMA, CEIADI MAN (Néron), OF.MVRRAN (r) (50-65) ; SENOM ; IVST, SEVER (70-90?), SEVER (75-100), (GERMANI, GERMANI F (75-100) ; FRONTINI (80-100).

192. Voir supra et dans Mees, 1995, p. 146 et 147, le cas actuellement exceptionnel du couple Gallicanus-N..., par rapport aux excmples de doubles signatures (moule et vase) du même potier.

193. Respectivement dus à Rutenos, Vibius, Volus et Lupus (Drag. 11), à Martialis? et Sabinus (H. 15a), à Albanus, Butio, Fuscus, Germanus III, Masculus, Quintus, Quintio et Vastus (Déch. 63), à Cobmitsus II, M. Crestio, Germanus III et à Vastus (Knorr 78), à Carillus et Crucuro (Déch. 67). Pour la datation des modèles voir par exemple Bémont et al., 1987, p. 28 et 29.

194. Par exemple RVTFNOS FEC AR, VIBI F, VOLVS, OF.AI.BANI, M. CRESTIO, GERMANIF.

195. [Mart]IALIS et trois des cinq signatures de Sabinus, inscrites en capitales rétrogrades dans le moule, témoignent incontestablement d'un effort de lisibilité.

196. Le lieu de production de bons exemples: les moules signés de Senilis, portant au fond un graffite et découverts au Rozier (une succursale de Ia Graufesenque) demeure incertaine (Bourgeois, 2002). 


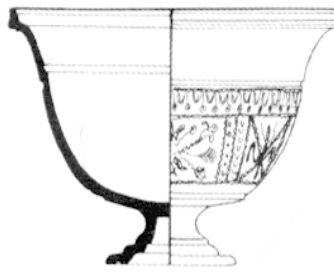

Drag. 11
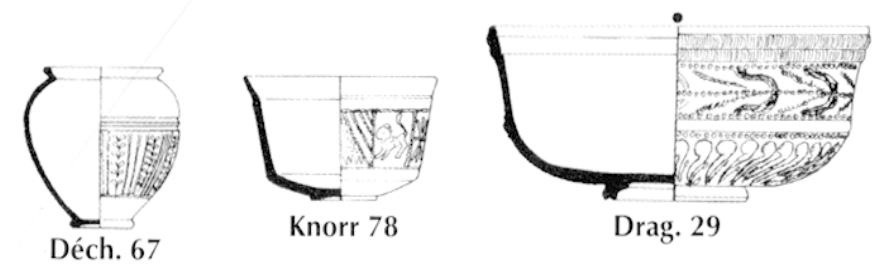

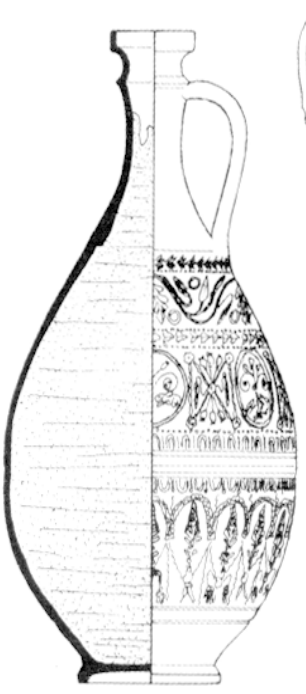

Her. 15
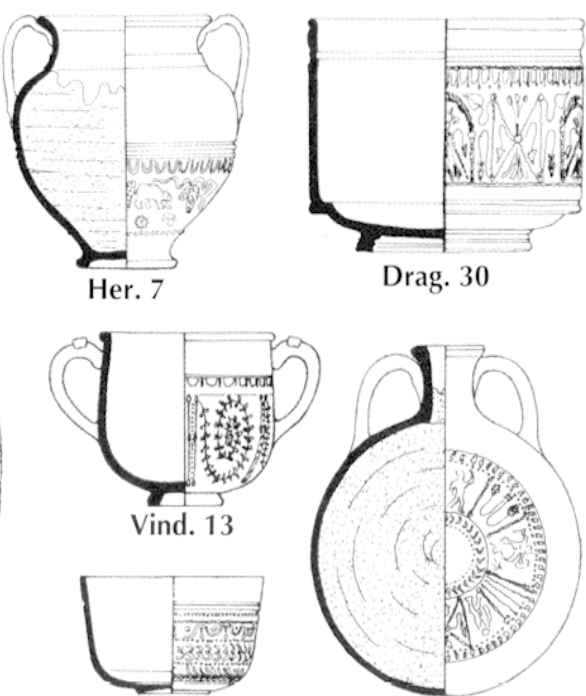

Her. 9

Déch. 63

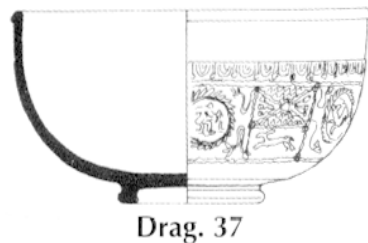

Drag. 37

Drag. 29

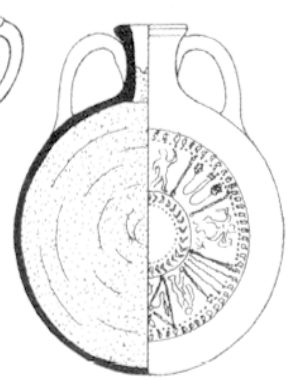

Fig. 63 - I. Craufesenque : principales formes décorées (d'après Vernhet, 1991, p. 49).

lors du tournage du pied, ils ne subsistent que dans les moules. Connus en moins grand nombre que les Drag. 29 ou 37 contemporains ${ }^{197}$, ces vases sont généralement produits dans les mêmes ateliers et ne présentent aucune particularité notable. Portant une seule signature (estampille ou graffite) généralement dans le décor, ils ne donnent la preuve ni de coproductions, ni de fourniture de moules à d'autres usagers.

I es bols hémisphériques Drag. 37 (60/65-milieu du II"s.) ont concurrencé les Drag. 29, puis les ont remplacés (fig. 63). Ils ne portent également que des marques issues du moule. Certains des signataires les plus tardifs (90-130) ont eu tendance à substituer l'estampille ${ }^{19 \%}$ au graffite, mais les deux modes de signature apparaissent cependant même chez les producteurs exclusifs de cette forme (fig. 64 et 65). Les poticrs

197. Certains décoratcurs comme Masclinus (60)-75) ou Masclus (50)-70) semblent toutefois s'être particulièrement intéressés à cette forme.

198. Certains potiers usent de marques directes en relief sur les vases: Aemil(ius), I. Cosius, $M$ Crestio, Crucuro (I et II), (jermanus (II, III et IV). Les autres utilisent des signatures dans des cartouches reproduites en creux et directes ou rétrogrades sur les vases. plus précoces, qui ont souvent fabriqué d'autres modèles, sont parfois, grâce aux Drag. 29, commus pour avoir alimenté d'autres potiers (ainsi Caluus, Mommo, Passienus), et/ou pour avoir assuré toute la chaîne de production (voir supra, p. 110). Mais les bols hémisphériques à eux seuls nous privent de ce genre d'informations. Ils présentent pourtant, à la différence d'autres types, des particularités épigraphiques, en petit nombre toutefois. Certains potiers pratiquent la double signature: estampille dans le décor et graffite en dessous - Bassinus (Trajan), Irontinus I (80-100) -, estampilles identiques dans et sous le décor - $M$. Crestio (90-110) - ou doublées dans le décor - Mercator (90-100 ?) -, sans que la signification de ces usages redondants soit évidente. En revanche quelques échantillons d'Amandus (115-130) et Biragillus (90-120) suggèrent, par l'association de marques différentes, de possibles collaborations ${ }^{199}$. Et les contenus respectifs des estampilles ou graffites incitent alors à attribuer aux signataires les plus discrets - Mas... et Ver... - la situation de l'employé ou du prestataire de services, même si leur rôle dans la fabrication du moule pouwait être prépondérant.

L'analyse d'un échantillon important de marques de La Graufesenque permet de souligner, outre la pauvreté relative de la population des vases ou moules décorés et signés, plusieurs phénomènes : outre la qualité normalement variable des sources épigraphiques (tributaires de la forme des supports), l'irrégularité de la conservation des échantillons, l'inégalité de leur répartition entre ateliers (partiellement imputable au hasard des découvertes), donc le caractère illusoire de leur représentativité. Certains exemples remarquables permettent cependant de relever, d'après les marques, la diversité probable ou certaine des rôles tenus dans la chaine de fabrication par les signataires de moules et de vases, mais laisse dans quelques cas (par exemple, les fabricants et usagers des sceaux) planer une incertitude sur le rapport entre la distinction des tâches et la division réelle dı travail. L'association de signatures différentes sur certains types décorés soulève, en particulier, le problème des relations structurelles à l'intéricur des ateliers ou entre fabriques supposées indépendantes. Le nombre de ces cas est cependant, par force, encore beaucoup trop limité pour que l'on puisse construire sans arbitraire des systèmes généraux, plus ou moins évolutifs, et donner le pas à la règle (contractuelle ??) plutôt qu'à des collaborations souples ou anecdotiques.

Il reste cependant que ces potiers du $\mathrm{l}^{\mathrm{cT}} \mathrm{s}$. ont ressenti le besoin de marquer leurs produits. Ils l'ont fait fréquemment, mais de façon souvent trop discrète ou peu lisible, - ou sans intérêt pour le client -, pour que l'on atuibue en priorité cet usage à autre chose qu'une nécessité liée à la fabrication des vases. I es estampilles sur vases lisses ne prendront donc localement tout leur intérêt que si elles peuvent être intégrées dans des problématiques assez larges : par exemple dans des études techniques at métrologiques de vases qui permettent de

199. OF AMANDI (1) e Mas (r) sous le décor d'um bol ; BIRACill dans le décor et Ve sous le décor d'un vase: Biragilli el Ver sous le décor d'un moule. I a signification d'un graffite numérique (XII) sous le décor d'un bol signé 1 .. COSI dans la frise estectle la même : L Cabsence d'autres reférences numériques identiques ne permen pas d'en juger. 


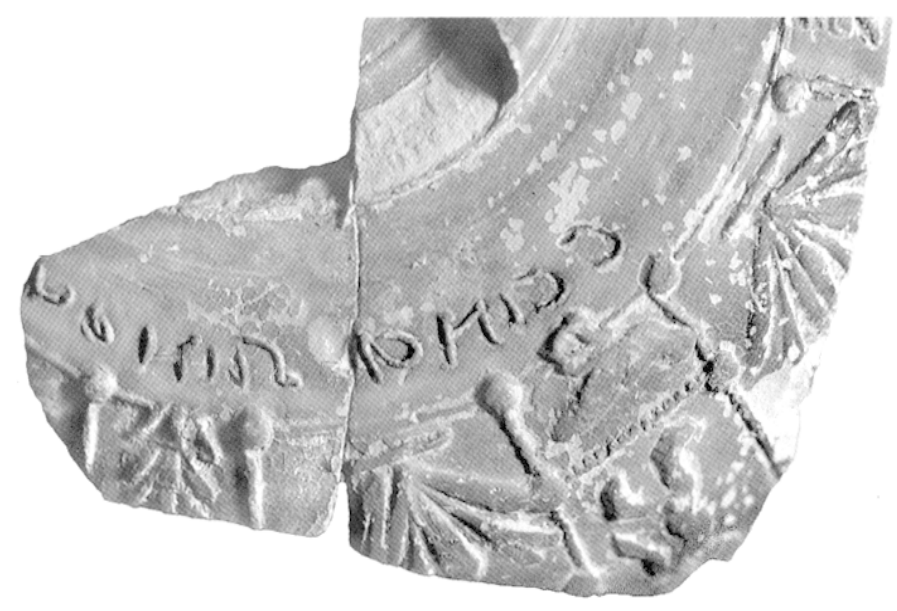

Fig. 64 - Glanum : bol Drag. 37 de La Graufesenque signé du graffite infradécoratif C.C.inci Siinou[iri] (de Caius Cincius Senouir [Trajan ?]) (cliché (:. Bémont, (iNRS).
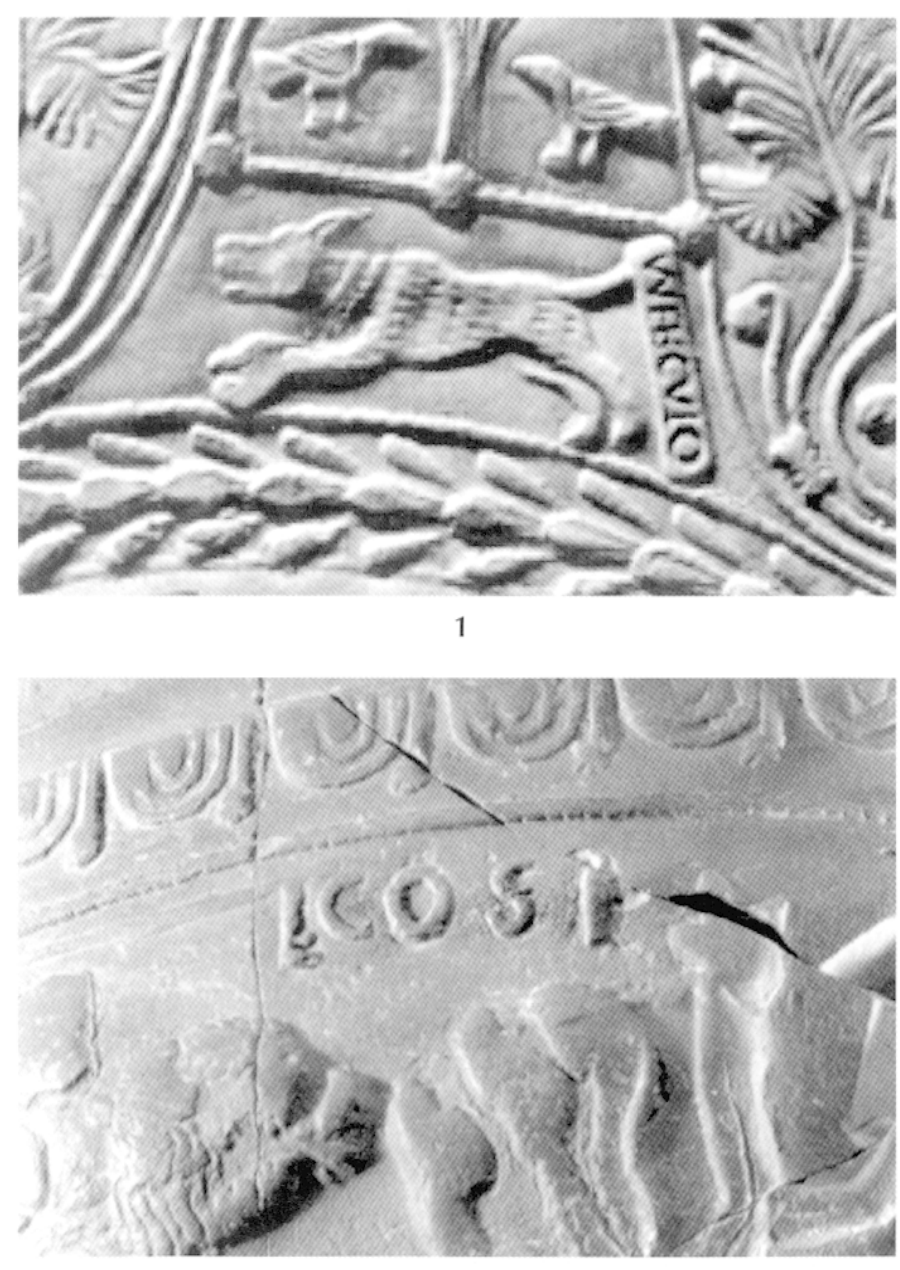

2

Fig. 65 - La (iraufesenque. Bols Drag. 37, marques intradécoratives estampillées issues des moules : 1, MIIRCATO (rétrograde et en creux, poinçon à vases lisses) ; 2, L.C.OSI (en relief, marque spécifique pour vases décorés) (1, d'après .Mees, 1995, pl. 130;2, cliche A. Vernhet, (.NRS). mesurer la coordination entre potiers du même centre (fig. 70) et l'évolution éventuclle des standards, ou si elles font l'objet de datations plus fines (celles que permet d'espérer l'Index des marques de Lecds) destinées à améliorer leur qualité de marqueurs archéologiques.

Les marques sur vases décorés doivent pour leur part être considérécs d'abord comme les indicateurs, précieux mais insuffisants, d'un système de production structuré. Il est donc indispensable, pour espérer faire progresser la connaissance de ces systèmes hiérarchisés de fabrication, d'associer au recensement des signatures de toutes sortes l'analyse stylistique du contenu des décors qui les accompagnent. Fondée sur des groupes d'échantillons, cette enquête doit prendre en compte des phénomènes de modes - illustrés par des principes généraux de composition, des thèmes et des types iconographiques -, puis passer à l'identification des poinçons individucls et des particularismes structurels propres très souvent à un décorateur ${ }^{200}$. Seule, ensuite, l'étude conjointe d'échantillonnages anonymes, naturellement plus larges que les groupes de pièces signées iconographiquement comparables, peut permettre de s'approcher de la solution des problèmes d'organisation professionnelle suscités par des pratiques complexes mettant en cause à la fois la fabrication des outils et celle des produits finis. Les questions de datation relative et d'évolution à l'intérieur les officines risquent cependant d'être toujours délicates, dans la mesure en particulier où la sigillée elle-même fournit fréquemment les indices chronologiques les plus fins pour la datation des horizons archéologiques qui seraient supposés la dater.

La fonction de la signature dépassait-elle le cadre de la fabrication? Les présomptions que l'on peut avoir reposent sur des exemples isolés. Ainsi Sabinus, à l'époque de Néron, inscrit sa marque de façon ostensible et la centre soigneusement dans la zone principale de vases exceptionnels : des lagènes (voir supra, fig. 58). De rares noms à la fin du $\mathrm{I}^{\mathrm{er}} \mathrm{s}$. et du début du $\mathrm{II}^{\mathrm{C}} \mathrm{s}$. (Germanus [groupes I-III], L. Cosius, Crucuro [série II]...), à la différence de beaucoup d'autres, étaient relativement grands, lisibles en creux de droitc à gauche dans les frises des moules ${ }^{201}$. Et ils produisaient sur la surface des vases de larges signatures (30 à $35 \mathrm{~mm} \times 7-8 \mathrm{~mm}$ ) bien lisibles. Que ces marques correspondent à une mode, c'est très probable (voir supra, p. 111). Qu'elles expriment un certain désir de reconnaissance s'expliquerait aussi par les aspects novateurs des décors de ces fabricants : création de poinçons et de structures originales (style libre animalier et grandes sinusoïdes) pour Germanus, vases à thèmes et à commentaires inscrits : victoire de Trajan sur Décébale ( $I$. Cosius) et scènes de combats dérivées, travaux d'Hercule (Crucuro). Mais la qualité d'autres décors signés - plus banals, voire médiocres - des mêmes atelicrs ne justifie pas cette revendication. Et la taille de ces estampilles ne suffit pas à faire des marques (comme il adriendra à I.ezoux à la fin du $I^{\prime \prime}$ s.) un élément à part entière de la décoration. Peut-on

200. Voir par analogie, Bémont et Rogers (1978 et 1979) et dans Mees (1995) les séries de bols rapportées à des sceaux homonymes (par exemple le cas de Germanus).

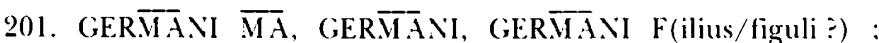
I. COOSI ; CRV':VRO 


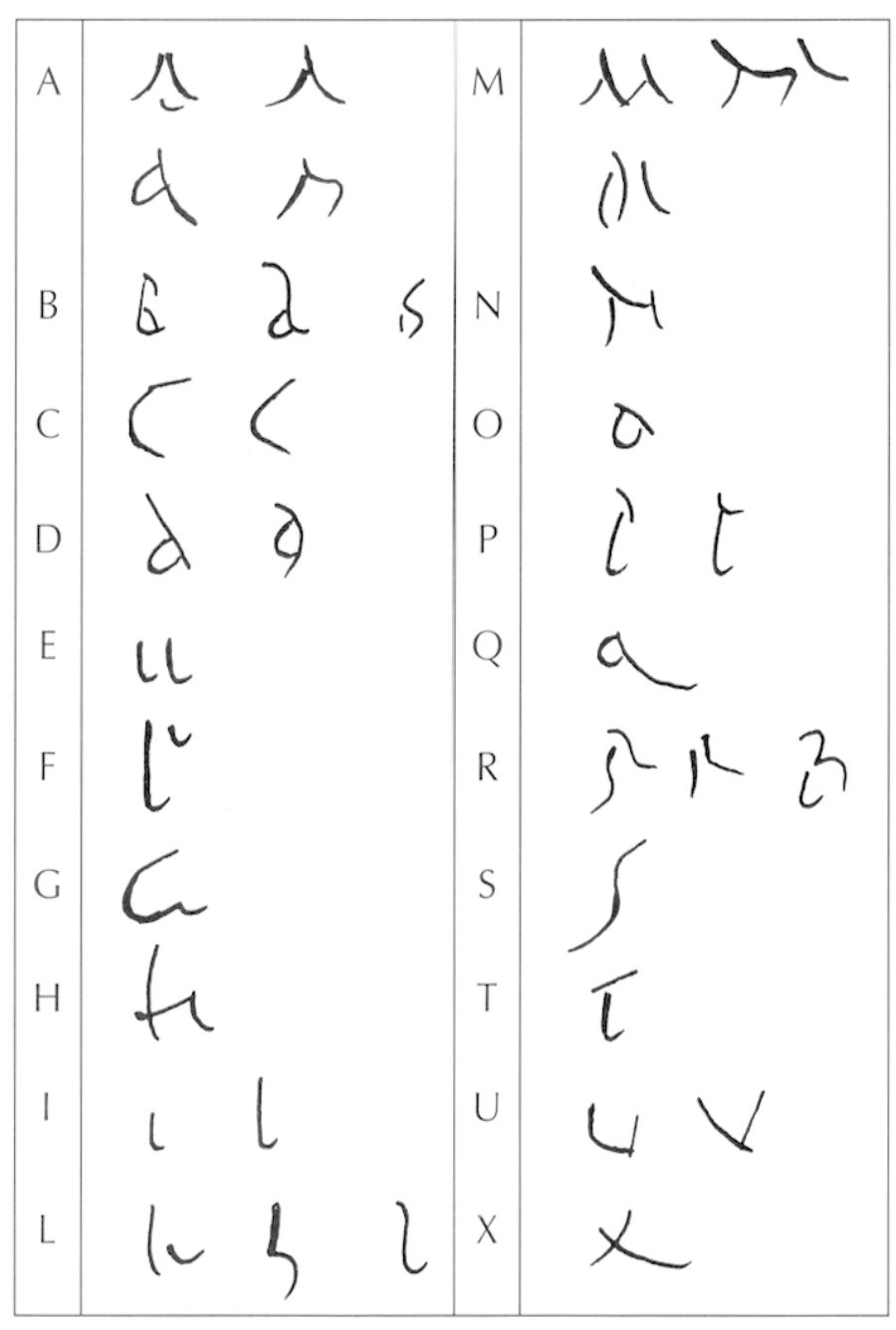

Fig. 66 - La Graufesenque : alphabet des comptes de potiers avec les principales variantes (d'après Bémont et al., 1987, p. 53).

parler de leur impact publicitaire? Il faudrait au moins démontrer par des décomptes le succès très remarquable des produits de ces potiers. Ce qui n'a pas encore été fait.

\section{LES COMPTES DE POTIERS}

Ces graffites furent principalement illustrés sur le site de La Graufesenque par un groupe de quarante et un textes, inscrits ante cocturam (" avant cuisson ") "212 sur des assiettes engobées, que découvrit $F$. Hermet au cours de ses fouilles entre 1901 et 1906 . Une première série fut publiée en $1904^{203}$

202. On doit cette constatation aux observations faites parallèlement sur les objets par L. Balsan et R. Marichal. Elle était de simple bon sens pour des céramologues avertis, la facilité des ductus des graffites étant incompatible avec la dureté des pâtes cuites. Mais on a travaillé trop longtemps sur photographies et respecté par tradition l'autorité des premiers éditeurs, dont la plupart étaient d'abord philologues et s'intéressaient de toute façon au texte plutôt qu'aux qualités physiques du support.

203. Des quatre pièces connucs comme découvertes par l'abbé Cérès deux ont été signalées en 1882 et 1884 dans le Bulletin de la Sociélé par l'inventeur, puis l'ensemble en 1923 et 1934. Ils furent dès l'abord interprétés comme des comptes de potiers. Et différents savants - français ou étrangers, philologues ou historiens ${ }^{204}$ leur consacrèrent, surtout entre 1924 et 1927, de multiples commentaires. Les découvertes de documents similaires se sont multipliées sur le site grâce à A. Albenque, L. Balsan et A. Vernhet, à l'occasion d'abord d'investigations entre 1950 et 1954 dans la partie est de la plaine de La Graufesenque, puis, à partir de 1965, de fouilles systématiques, dans l'ouest, sur la propriété Malaval acquise par l'État. La plupart de ces graffites donnèrent lieu à des articles. R. Marichal reprit finalement les cent soixante-neuf comptes exhumés jusqu'en 1980 et les réunit avec des graffites sur accessoires de potiers et vases en céramique commune, et avec d'autres documents utilisant les vases comme supports (courtes inscriptions comportant surtout des noms propres, contrats) pour publier en 1988 une remarquable édition de texte, fondée en particulier sur une rigoureuse critique paléographique et linguistique et assortie d'un essai d'interprétation. Après la présentation succincte de deux nouveaux comptes importants en 1991 et 1993, la plupart des derniers compléments connus à ce jour - dix-sept comptes fragmentaires et vingt-deux courts textes - ont été intégrés par P.-Y. Lambert dans le récent volume des $R I G$ (p. 85-146) paru en 2002. Certains y ont fait l'objet, avec les sections gauloises des graffites Marichal, d'une étude philologique approfondie ${ }^{205}$.

\section{LES GRAFFITES}

Ces textes ont été inscrits à la pointe sèche dans l'argile crue, après engobage, sur le fond d'assiettes ou de plats souvent estampillés, qui ont ensuite été cuits. Le vase inscrit parfois bien conservé dans un dépôt (fouilles Hermet) fut quelquefois aussi réduit en fragments, utilisés par exemple pour recharger une rue de l'atelier (fouilles Vernhet à partir de 1971). Dans les meilleurs cas, les qualités du support (pâte, couleur, morphologie), ses cassures et l'écriture ont alors permis le remontage plus ou moins poussé des puzzles.

La cuisson prouve que les textes devaient être conservés : les assiettes inscrites ne pouvaient guère jouer leur rôle fonctionnel et d'ailleurs aucune ne porte de traces normales d'usure. Leur abandon, ou surtout leur bris délibéré montrent aussi que l'intérêt du document écrit était temporaire. L'écriture est une cursive latine du Haut-Empire (fig. 66). Et les variations que l'on observe dans la graphie des lettres, et que l'on impute aux habitudes des différents scribes, ont permis à $\mathrm{R}$. Marichal de définir plus de trente « mains " ${ }^{2 \%}$. La langue est un latin

nationale des Antiquaires de France, deux, communiquées à Héron de Villefosse en 1893 pour étude. Elles ont toutes été longtemps considérées comme perdues (Marichal, 1988, p. 3). Une, peut-ĉtre deux ont ćté retrouvées en 1963 par $\mathrm{H}$. Comfort dans les collections du Louvre. 204. Voir Marichal, 1988, bibliographie, p. XI.

205. Références utilisées dans le cours du texte : Mar. 1-213 (Marichal, 1988) ; VB 1 (Vernhet, Bémont, 1990-1991) et VB 2 (Bémont, Vernhet, 1992-1993); 1 -30a à $\mathrm{L}-30 \mathrm{q}$ et $\mathrm{L}-98$ (I ambert, 2002).

206. Une partic des fragments quil a édités et ceux du Recueil des inscriptions gauloises (Lambert, 2002) permettent de supposer que les scribes étaient beaucoup plus nombreux. 
vulgaire, mêlé de gaulois dans des proportions variables. Les particularités orthographiques caractérisent, pour les plus cohérentes, les désinences des noms propres au nominatif et pour les plus aléatoires, les noms des vases. Au moins une cinquantaine de ces documents comportent des traces de titres (courts paragraphes placés en tête des listes) dont le vocabulaire contribue particulièrement à justifier la distinction grossière établie avec prudence par R. Marichal entre un groupe " latin " et un groupe "gaulois ", bien que l'on observe de fréquentes contaminations dans la rédaction des textes des différentes séries (Marichal, 1988, p. 71 et 72). Ces ensembles eux-mêmes ont été divisés, dans la mesure du possible, en sousgroupes plus ou moins homogènes en fonction de leur contenu et des circonstances de leur découverte. Mais, à l'heure actuelle, les trois quarts des échantillons résistent à ces partages, du fait de leurs particularités, mais aussi, le plus souvent, de leur lamentable état de conservation (en particulier Mar. 35 à 45, 48, 50 à 73, 78 à 82, et surtout 100 à 162). Dans la mesure en tout cas où les graffites ont été situés dans des fourchettes assez étroites, on notera que le texte le plus ancien (L-30c) est gaulois, que l'emploi de cette langue, parallèlement au latin, est bien attesté dans des graffites datés de Néron ${ }^{207}$, et qu'il persiste encore entre 50 et $80{ }^{208}$, sous Vespasien ${ }^{209}$, voire plus tard ${ }^{210}$. Les noms de vases étant pour la plupart communs aux deux séries, et les noms des potiers, souvent mixtes, il est évident que l'extrême morcellement du mobilier joue (abusivement ?) en faveur du latin.

Le fait que les supports aient été produits en même temps que les vases à cuire et portent jusqu'à présent toujours un nom estampillé différent de ceux de la liste associée (fig. 67, 68 et 72) a contribué à faire accorder à ce potier (pour la fournée concernée) un rôle à part : responsable de la cuisson et éventuellement de lots de vases comptabilisès parfois en tête des listes sans nom de responsable (par exemple Mar. 10, 13, 17, etc.). Si les prérogatives du maître-fournier et la nature de son mandat font l'objet de discussions, cette identification hypothétique est le plus souvent assez bien acceptée.

\section{CONTENU ET IDENTIFICATION}

F. Hermet, qui édita les premiers graffites, les mieux conservés et les plus homogènes, et $\mathrm{A}$. Oxé, leur premier commentateur allemand, ont suggéré de reconnaître dans ces textes des bordereaux d'enfournement. Cette hypothèse se justifiait d'abord par le contenu des textes connus à cette époque. Plusieurs éléments disposés en ligne y figuraient dans un ordre constant: le nom d'un homme (identifié souvent d'après des marques de potiers estampillées), celui d'un type de vase (certains, comme catillus " assiette", étant bien connus dans des textes littéraires), parfois précisé par un qualificatif ou

207. Mar. $3,4,6,7,8.12,14,16,19,22,23,30,32,33,46,85$, L-30a. 208. Mar. 45,90 .

209. Mar. $34 ?, 86,89$, L-30d.

210. Fin du $\mathrm{I}^{\mathrm{cr}}$ s. : $\mathrm{L}-30 \mathrm{~b} ; 70-90: \mathrm{L}-30 \mathrm{j}$ (fragment réunissant des noms latins et d'autres à désinence gauloise).

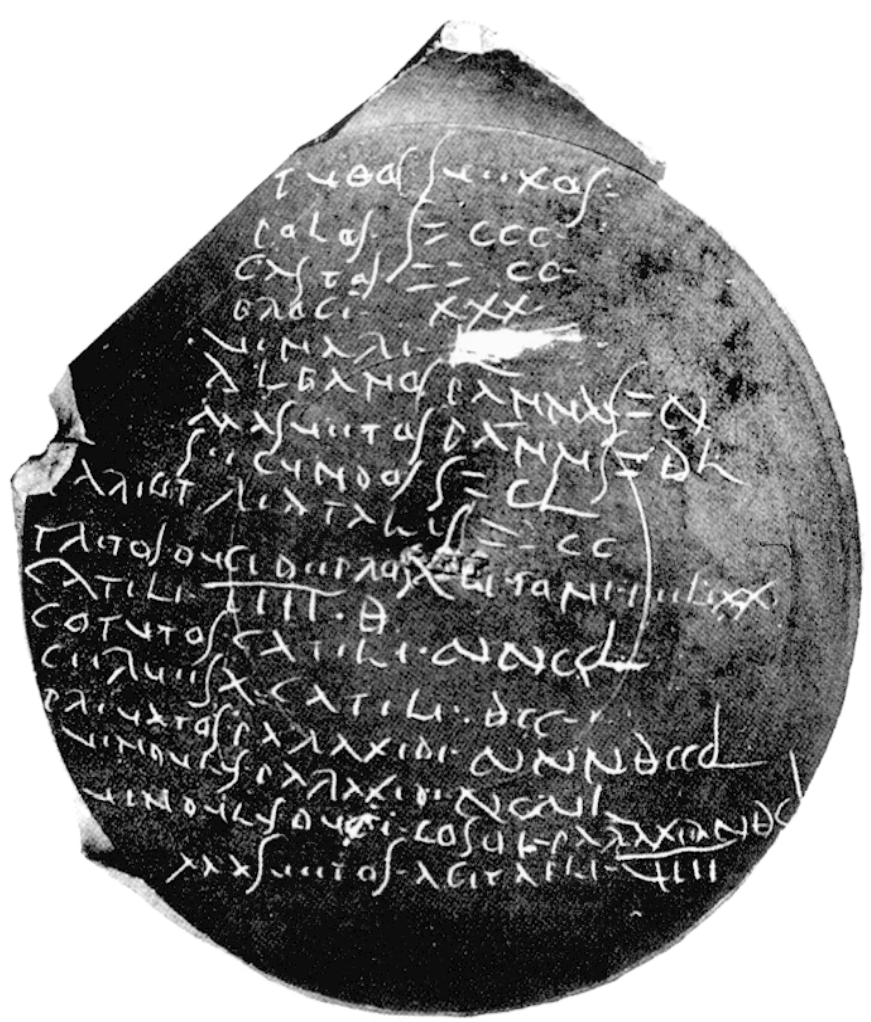

Fig. 67 - La Graufesenque : graffite "gaulois" de la série Hermet (Mar. 12) [Claude-Néron] ; estampille: MARTI (d'après Hermet, 1934, II, graffite $n^{\circ}$ 1).

une mention de taille ${ }^{211}$ (celle du diamètre), enfin un nombre (de quelques dizaines à plusieurs milliers). Le même schéma se répétait, organisé le plus souvent en colonnes (voir par exemple Mar. 25, 28, 46, etc.) ${ }^{212}$. L'ordre respecté dans la plupart des cas plaçait en tête et en petit nombre (quelques dizaines ou centaines) de grands vases - en général les mêmes ${ }^{213}$, souvent détaillés selon leurs dimensions -, dans la deuxième partie d'autres vases, en général sans dimensions et le plus souvent par milliers. Le soin apporté au classement par types et tailles faisait souvent paraître, dans ces premiers documents, deux ou plusieurs fois le même potier ${ }^{21.4}$ dans le même compte, en fonction de ses produits - ainsi Masuetos, fournisseur de modèles très divers, dans Mar. 13, 15, 16, etc. -.

211. Ces dimensions mentionnant le pied et ses fractions sont abrégées ou orthographiées plus ou moins exactement: pedalis (d'un pied: $29,6 \mathrm{~cm}$ ), bessalis (ou $\mathrm{S}=$, de $2 / 3$ de pied), triantalis (ou $==$, de $1 / 3$ de pied), pour les cas les plus fréquents. D'autres dimensions, $=$ (sextantalis, ou de $1 / 6$ de pied), $S$ (semis, ou $1 / 2$ pied) sont beaucoup plus rarement attestées.

212. Cette structure est parfois remplacée par une présentation en paragraphes, voir par exemple Mar. 74.

213. En particulier canastri, mortari, pannas, vinari.

214. Le nombre des potiers différents dans les 21 graffites Hermet, actuellement les mieux conservés (Mar. groupe 1), la de 5 à 15 étant entendu que la grande majorité des groupes comprennent entre 5 et 10 participants. Quinze listes présentent des répétitions. 


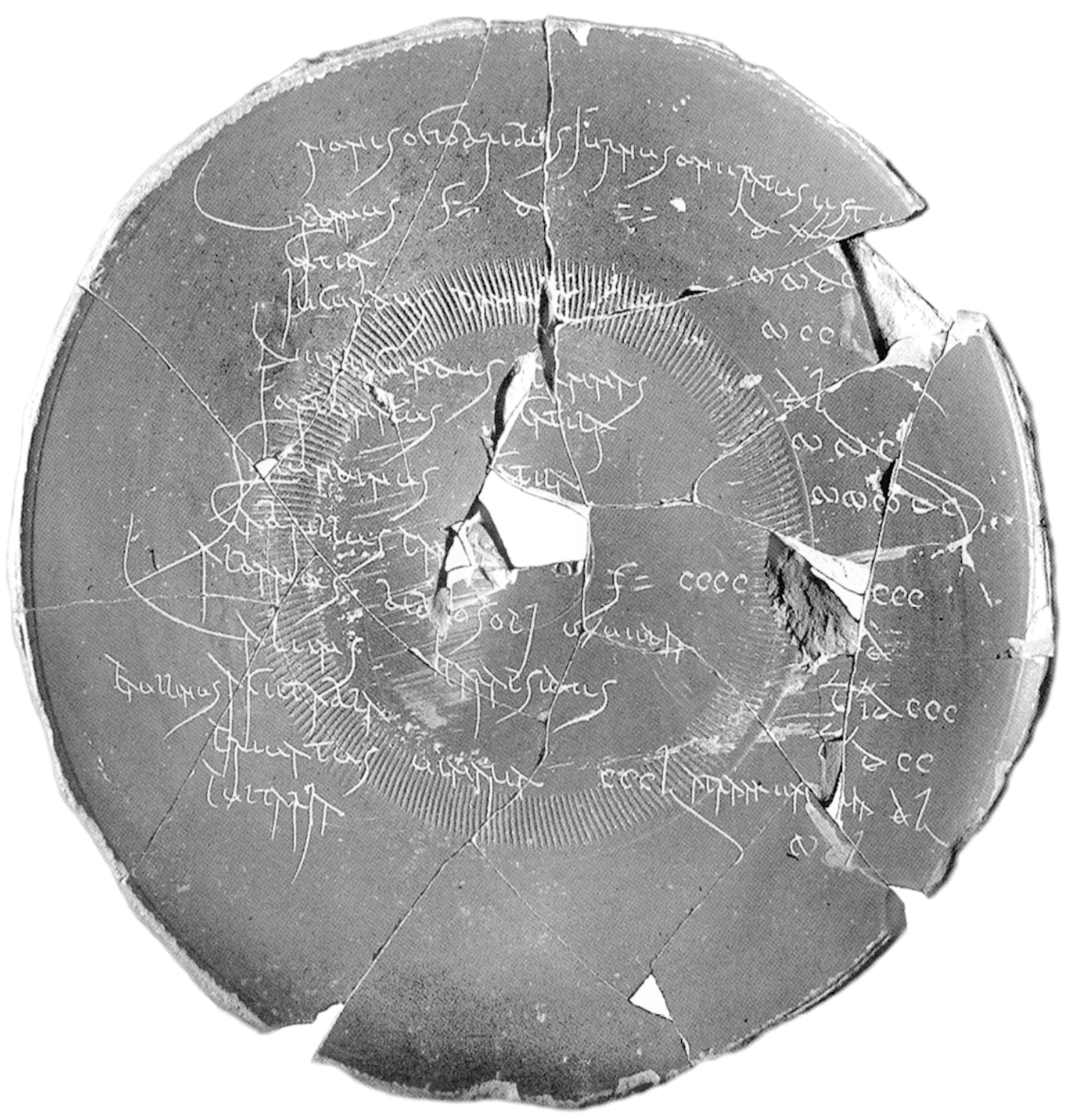

Fig. 68 - La (iraufesenque : graffite "latin"VB 2 [Vespasien]; estampille : COS.RVFIN (cliché A. Vernhet, CNRS).

Enfin, le total (summa ou summa uxsedia ${ }^{215}$ ) des vases (environ 30000 pièces ou plus) était conservé à la fin de six listes. Ces particularités incitèrent toutes à recomnaitre des documents comptables mettant en cause des potiers intervenant atu même titre, mais ne semblant pas être régulièrement associés. Comme le montre le tableau XI une série d'autres comptes, dépourvus de summa et parfois incomplets, fait apparaître la vaiscmblance de chargements réguliers supérieurs à $25 / 26000$ pièces. Malheureusement trop peu sont extérieurs au groupe Hermet, ce qui interdit d'envisager la moindre tendance à une modification du rythme de fourniture.

L'hypothèse d'une cuisson associéc sous la responsabilité d'un expert fut proposée par A. Oxé en 1925 et reprise par l'ensemble des commentateurs. Le fait, alors inconnu, que ces listes étaient enregistrées ante cocturam "avant cuisson " ne pul

215. Sur la signification de ce qualitatif (= maximal, de qualité/taille supérieure, etc.) voir Marichal. 1988, p. 100, et Lambert, 2002. p. 114 et 115 . être utilisé. Mais la périodicité des opérations, la relative régularité des nombres en cause, la diversité des participations des potiers trouvaient dans cette lecture une justification. En revanche, l'hypothèse "commerciale " de bordereaux d'expéditions ou de commandes - suggérée en 1904 par J. Déchelette (vol. I, p. 91) sur la base des quelques premiers échantillons n'aurait pu à elle seule expliquer la répétition et la régularité du groupement de telles quantités de mobilier. On tira également argument du libellé des en-têtes coiffant une partie des listes. Les textes gaulois (fig. 67) des hapax mirent à l'épreuve la sagacité de Loth et Vendryès qui, en 1924, purent interpréter le mot $t 11 \theta$ os suivi de différents ordinaux ( $\operatorname{cintux} 216$ " premier?" alos " deuxième ", ... decametos " dixième ") qui impliquaient un ordre, une succession. Le sens général de "groupe ": d'où collection, et aussi compte, addition, facture, équipe, qu'ils

216. Voir en dernier lieu I ambert. 2002, p. 112, sur le sens de cet arljectif. 
Tabl. XI - Les comples chiffrables les mieux conservés de La Graufesenque.

\begin{tabular}{|c|c|c|c|c|c|c|c|}
\hline $\mathrm{N}^{0}$ & Summa ${ }^{(1)}$ & Uxsedia & $\begin{array}{l}\text { Summa } \\
\text { sup. }(2)\end{array}$ & $\begin{array}{l}\text { Summa } \\
\text { inf. (2) }\end{array}$ & Réelle & Incontrôlable (3) & Restitution (4) \\
\hline 17 & 30100 & & $x$ & & & $x$ & \\
\hline 18 & 34725 & $x$ & & & & $x$ & \\
\hline 20 & $3025 ?$ & $x$ & $x$ & & & $x$ & $x$ \\
\hline 22 & 33500 & & & $x$ & 33845 & & \\
\hline 23 & 28500 & $x$ & $x$ & & 27735 & $x$ & \\
\hline 28 & $?$ & $x$ & & & & $x$ & \\
\hline VB 1 & 30355 & $x$ & $x$ & & 19925 & & \\
\hline
\end{tabular}

\begin{tabular}{|c|c|c|c|c|c|}
\hline \multicolumn{3}{|c|}{ Entiers } & \multicolumn{3}{|c|}{ Mutilés } \\
\hline $\mathrm{N}^{0}$ & Totaux & Particularités & $\mathrm{N}^{0}$ & Totaux & Incomplets (5) \\
\hline 10 & 30350 & & 7 & 29915 & $x$ \\
\hline 4 & 30010 & & 3 & 29825 & $x$ \\
\hline 16 & 29845 & & 6 & 29110 & $x$ \\
\hline 85 & 29740 & & 2 & 28693 & $x$ \\
\hline 21 & 27990 & texte corrigé & 5 & 28420 & $x$ \\
\hline 1 & 27945 & & 15 & 25480 & $x$ \\
\hline 13 & 27930 & & 12 & 25380 & incomplet? \\
\hline VB 2 & 26930 & & 8 & 25195 & très \\
\hline 12 & 25380 & complet? & 9 & 23205 & très? \\
\hline \multirow{2}{*}{14} & \multirow{2}{*}{$\begin{array}{c}25070 \\
\text { ou } \\
28070\end{array}$} & \multirow{2}{*}{ * } & 47 & 20650 & très \\
\hline & & & 11 & 19450 & très \\
\hline & & & 83 & 16750 & très \\
\hline & & & 46 & 11880 & très \\
\hline
\end{tabular}

proposaient, fut repris par A. Oxé et étendu au sens plus concret de «fournée ». La publication (Duval, Marichal, 1966) de graffites " latins " comportant dans leur titre les mentions parallèles: furnus secundus ("deuxième " Mar. 74) et furnus pri/mus] ("premier » Mar. 83) permit au moins de mettre incontestablement les graffites en rapport avec le four (furnus) ${ }^{217}$ ou la fournée? sinon d'établir l'équation linguistique furnus $=t u \theta o s$ (ce dernier vocable n'ayant aucune affinité étymologique avec rien qui concerne la cuisson). Les dates (entre mars et octobre), parfois associées dans les titres latins les mieux conservés à ce furnus numéroté (Mar. 74 : Furnus secundus...idus Maias) suggéraient un ordre chronologique et un possible passage de four à fournée. Le remontage en 1976 d'un fragment de plat inscrit restitua enfin dans un titre la formule oneraui furnum ( «j'ai chargé le four/la fournée ») "18, confirmée à son tour en 1991 et 1993 (fig. 68 et 72) par la mention furnus $X$ oneratus est (" le four/la fournée $\mathrm{X}$ a été chargé "), et conforta l'hypothèse de comptes de cuisson proposée en 1925, sans toutefois fixer la signification de furnus: onerare, comme " charger " en français, étant compatible avec les deux acceptions proposées. Seul le parallélisme avec

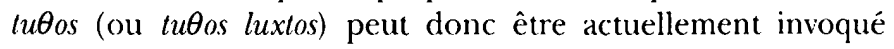
(voir Marichal, 1988, p. 95, 99 et 100) pour rapporter furnus à une collection d'objets (à cuire) plutôt qu'au lieu de leur cuisson 219 .

217. Furnus désigne dans le latin classique le four domestique, non le four industriel (fornax). Nous ne disposons pour la sćrie latine que d'une numérotation très sporadique.

218. Ces textes éclairent les fragments mutilés des titres de trois graffites (Mar. 48, 66 et 75) conservant quelques lettres explicables par onerare ou oneratus.

219. La formule incipit furmus primus attestée une fois (Mar. 83) et indiquant le démarrage d'un furnus ne représente qu'une approximation linguistique supplémentaire pour signifier le début des opérations de cuisson ou du chargement préalable.

\section{LA DATATION DES GRAFFITES}

Ces textes mettent chacun en cause un nombre restreint d'individus fournisseurs de vases: quinze une fois (Mar. 19), mais généralement moins, sur moins de cinquante documents utilisables. Une part notable d'entre eux, homonymes de potiers attestés à La Graufesenque par des marques estampillées, ont habituellement été utilisés comme indices chronologiques (l'activité de ces fabricants étant elle-même datée par les sites consommateurs sur lesquels étaient découverts leurs produits). Encore fallait-il que cette estimation fît compatible avec la datation de la signature souvent imprimée au centre de l'assiette-support encore crue et celle, souvent plus large, du type de cette dernière. Outre ces qualités intrinsèques ont été évidemment prises en compte, au moins pour une partie du mobilier découvert par A. Vernhet depuis 1971, les références stratigraphiques ${ }^{220}$, assez larges en l'occurrence. Ces éléments fournissent pour la plupart des échantillons et, en l'absence actuelle de datations fines des estampilles d'assiettes, une approximation de cinq (L-30c : 35-40) à quarante ans (Mar. 93 et 94 : Claude-Vespasien), selon que les indices, plus ou moins nombreux, se prêtent à des recoupements plus ou moins restrictifs. On constate ainsi que la plus grande partie des bordereaux datables se situent entre Claude et Domiticn, c'està-dire pendant la période de grande prospérité de La Graufesenque, bien que la série gauloise des graffites Hermet (Claude-Néron), compte tenu de sa qualité et de sa relative homogénéité, continue à peser très lourdement sur l'appréciation de l'ensemble.

Paradoxalement, nous disposons par ailleurs d'un certain nombre de repères chronologiques précis, du moins pour les potiers, mais pour nous peu utilisables. Comme nous l'arons signalé (voir supra, p. 115), une trentaine au moins des graffites

220. Il s'agit essentiellement à partir de 1973 de la couche $2 b$ datée par A. Vernhet de 40-100. 
gaulois et plus d'une dizaine des latins présentaient en haut du compte une sorte de titre que les comparaisons entre les deux séries permettent d'interpréter globalement. Dans les bordereaux gaulois ${ }^{221}$, composés en grande partie des graffites Hermet ${ }^{222}$ réunis par $\mathrm{R}$. Marichal dans le groupe I, vingt-deux présentent, plus ou moins conservée, la mention tüos accompagnée d'un nombre ordinal écrit en toutes lettres ou transcrit en chiffres romains. Ce dernier ne dépasse que deux fois le nombre dix (Mar. 46 : XIIII ; Mar. 30: LV), que l'on estime, d'après l'ensemble des en-têtes conservés et aussi selon la vraisemblance, comme pouvant représenter la somme moyenne des fournées annuelles, soit environ $300000 / 400000$ vases. Cinq graffites (Mar. 2, 4, 8, 11, 19) portent en outre la mention cas(s)idan(n)os, accompagnée d'un ou deux noms propres ${ }^{223}$. Ce personnage est tenu par les philologues, d'après d'autres composés de *dann, pour une sorte de responsable, de magistrat, dont les fonctions précises (cassi ?) sont dans ce cas encore incertaines (Lambert, 2002, p. 111 et 112), mais qui sert apparemment de référence à la rédaction des comptes.

Certains détails posent des problèmes plus complexes : ainsi l'adjonction, au-dessus de tu $\theta$ os decometos dans Mar. 1, de la formule autagis cintux XXI. R. Marichal (1988, p. 96-98) a proposé l'équivalence : $10^{\circ}$ fournée $=21^{\circ}$ (fournée) du $\mathrm{I}^{\mathrm{er}}$ Autagis et suggéré de reconnaître dans l'autagis une unité (de temps) supérieure à la succession annuelle des $t u \theta o i$, et en rapport peut-être avec le comput gaulois par lustres (durées de cinq ans). Cette hypothèse permettrait de rendre compte des nombres de fournées supérieurs aux 10/11 supposées annuelles, étant entendu que LV fournées (Mar. 30) par an seraient à la fois sans doute difficilement réalisables et vraisemblablement pléthoriques, compte tenu des quantités de vases actuellement recensées, à la même époque, pour une fournée (30000 × 55 !). Si cette hypothèse séduisante se vérifiait, elle mettrait en évidence la persistance locale dans un milieu professionnel d'un système gaulois de calendrier, parallèlement au calendrier romain. En revanche, les références mensuelles font actuellement défaut dans les séries gauloises: même si deux fragments de titres (Mar. 28, 32) comportent l'un ...JAugustas, l'autre alugusti, aucune relation explicite avec un mode de datation du tüos n'apparaît sur ces tessons.

Les graffites latins présentent un système de datation parallèle sans être identique (fig. 68) : la mention du chargement (voir supra, p.117) de "fournées" (furnus), numérotées à l'aide d'ordinaux, dépassant une fois dix (Mar. $66:$ XVI) et (à l'ablatif) les noms de magistrats/prêtres annuels, renouvelables au moins trois fois (Mar. 74, VB 1, L-30e) et nommés flamines. Cet ablatif absolu ("X étant flamen ") permet de reconnaître dans ces personnages, donc par analogie dans les cassidannoi, au moins les magistrats éponymes servant de référence annuelle à l'opération enregistrée. La mention, malheureusement trop souvent mutilée, du mois et du jour (fig. 68 et 72)

221. Pour l'ensemble de ces traces voir Lambert, 2002, p. 85 et 91 et L. $30 \mathrm{a}$ à $\mathrm{d}$.

222. Sur 22 échantillons utilisables, 5 sont extérieurs à cette série: Mar. 29, 30, 46, L-30c et d.

223. Sur l'éventualité d'un troisième, voir Lambert, 2002, p. 109-111. permet d'accroître de quelques unités la liste des échantillons " avec titres" et les dernières découvertes confirment que ces opérations n'ont laissé de traces avérées qu'entre mars (Mar. 81) et octobre (VB 2), ce qui est compatible, selon les céramistes modernes, avec le climat local. L'état de ces titres est malheureusement si mauvais et les exemples sont si sporadiques qu'il n'est pas possible de déterminer une relation régulière, cyclique, entre mois et numéros de fournées.

La question principale, malgré ces précisions illusoires, est posée par l'absence totale de référence au calendrier officiel, qui interdit de dater chaque document, de savoir sur quelle période exacte s'étendent ces témoignages et quel laps de temps sépare un graffite d'un autre.

\section{LES NOMS DE POTIERS : LEURS RAPPORTS AVEC LES ESTAMPILLES}

Dans les graffites publiés en 1988 sont mentionnés 140/150 potiers, pour une part inconnus dans les signatures sur vases. Leur nombre total a augmenté à l'occasion des découvertes plus récemment publiées ${ }^{224}$. Et l'on peut aisément imaginer la croissance du nombre des inconnus dans le texte des échantillons tardifs, compte tenu de la disparition des estampilles nominales, à partir de la fin du $\mathrm{I}^{\text {er }}$ s., sur la plupart des formes nouvelles de coupes et d'assiettes ${ }^{225}$ appartenant aux six services dits " flaviens" (Vernhet, 1976). L'excellente étude de R. Marichal (1988, p. 71-74 et 264-270) a mis en évidence la diversité des noms : de racines celtiques, latines, celto-latines ou grecques, et la variété, plus grande encore, des formes qu'ils peuvent prendre. Les noms les plus courants - à thèmes en -oprésentent, en effet, des nominatifs latins à désinence en -us, gaulois à désinence en -os. En fait, il advient fréquemment que les uns ou les autres prennent une terminaison en -os ou en -us selon le gré des scribes. Ainsi l'alternance entre formes latines et formes gauloises des mêmes noms est naturelle et largement constatée entre graffites " latins " et graffites " gaulois ". Mais, par ailleurs, certaines fantaisies sont observées à l'intérieur même des séries gauloises ou latines. Ainsi les recensions de R. Marichal montrent que sur soixante-huit noms différemment orthographiés dénombrés dans les graffites " gaulois ", quarante-sept (dont seize celto-latins/grecs, dix-huit latins) présentent une finale gauloise en -os ou -0 , mais vingt et un (dont quatre celtes et six celto-latins/grecs) un nominatif en -us. Il apparait également que, dans ce groupe, les mêmes noms peuvent présenter une orthographe tantôt gauloise, tantôt latine. On rencontre ainsi Albanos/o et Albanus, Albinos et Albinus, Cornutos/o et Cornutus, Regenos ${ }^{226}$ et Reginus, Summacos

224. Un exemple remarquable est fourni par 1-30e (Lambert, 2002, p. 94 et 95) trouvé en 1986 près du grand four et daté de l'époque Domitien-Trajan : cinq des huit noms de potiers préservés sont actuellement incomus à la Graufesenque, deux autres (Donatus et Victor), sauf erreur de datation du graffite, paraissent attestés localement par des homonymes à une autre époque. le dernier (Fortunatus) figure dans VB 2.

225. Seul le service E conserve l'usage des marques épigraphiques, mais son déclin commence dès la fin du $\mathrm{I}^{\mathrm{er}} \mathrm{s}$.

226. Reginos est maintenant atteste : $1 .-30 \mathrm{j}$, face $\mathrm{Bl}$. 
et Summarus parmi les celto-latins, Masuetos et Masuetus, Secundos et Secundus, Verecundos/o et Verecundus parmi les latins, Lousios et Lousius, Tritos et Tritus parmi les celtes. Un phénomène symétrique de mixité peut être observé dans les graffites latins.

On a suggéré également que certaines formes typiquement gauloises dans les graffites se retrouvaient latinisées dans les estampilles - comme $S \cot (t) a$ attesté dans des bordereaux datés de Claude-Néron était peut-être latinisée en Scottius: nom connu par des estampilles à La Graufesenque entre 20 et $\mathbf{5 5 . 5}$. On a montré aussi qu'on pouvait éventuellement soupçonner parfois pour des synonymes la traduction du gaulois en latin : ainsi Tritos et Tertius. Il n'en reste pas moins que, malgré ces accommodements orthographiques ou linguistiques, une part importante des noms inscrits dans les bordereaux - environ $40 \%$ - sont jusqu'à présent inconnus par les estampilles (toutes, rappelons-le, rédigées en latin). Or les formes onomastiques manquantes ne sont pas nécessairement gauloises. Et, compte tenu de la dispersion aléatoire de la sigillée de La Graufesenque, de l'ampleur de son aire de diffusion et de la multiplicité des publications, il paraît peu probable que de nouvelles découvertes réduisent totalement ou même très considérablement ce déficit. Il semble donc évident qu'une forte proportion des producteurs alimentant les fours ne signaient pas les vases. Quelles étaient leurs fonctions? Produire des vases anépigraphes, pourquoi ? Nous ne disposons pas, en tout cas, d'évaluations permettant de mesurer pendant cette période la part relative des pièces signées et des autres ${ }^{227}$. Signaient-ils d'un autre nom que le leur et travaillaient-ils, en qualité de sous-traitants, pour des potiers "à signature ", des officinae? ${ }^{228}$. Où se situe la différence (hiérarchique ?) entre signataires et non-signataires, alors que la qualité de tous les vases ètait uniforme pour assurer le chargement équilibré et la réussite des fournées?

Pourquoi les comptes du fournier mettaient-ils les nonsignataires directement et personnellement en cause? Autre fait notable en effet : les participants aux fournées ne se différencient dans chaque bordereau que par le type et le nombre des pièces fournies, mais ils paraissent tous placés sur le même plan, ils portent tous un nom unique, celui sans doute qu'ils utilisaient dans la vie courante, et rien dans ces textes ne suggère entre eux une hiérarchie sociale ou professionnelle. Ces documents ne leur reconnaissent, en somme, d'existence qu'en fonction d'une opération: la réunion en vue de la cuisson d'une quantité importante de mobilier.

Ce phénomène est pour nous d'attant plus remarquable par sa permanence que nous disposons d'un matériel très hétérogène et que les équipes réunies n'y sont pas constantes, même si elles sont apparentées. R. Marichal (1988, p. 107) a montré, en effet, la cohérence de son groupe 1 , relativement

227. Notons que la fosse dite de (állicanus, découverte voilà quelque vingt ans (Bémont, 1987) et datée vers $55 / 60$, a surpris les inventeurs par la pratique de l'estampillage, quasi générale sur presque tous les types sigillés. En revanche, une ou deux formes rares n'étaient jamais signées.

228. Je ne retiens ici que l'hypothèse "optimiste " : l'identité des homonymes intéressés par les graffites et les estampilles. bien conservé et composé de vingt-neuf documents trouvés sur le même site. Cét ensemble, constitué de quarante-six potiers, utilise les services d'au moins neuf scribes, mais le nombre des individus associés à une fournée dépasse exceptionnellement dix et les groupes de potiers réunis pour chaque occasion, bien que souvent proches, ne sont pas identiques.

Ce cas est actuellement unique. Pourtant on ne sait pas, étant donné les conditions de datation des documents, si les différences de participation obscrvécs dans cette nébuleuse tiennent à une organisation souple entre habitués et à des conventions temporaires conclues au coup par coup, selon les possibilités de chacun, entre le potier et le responsable du four, ou si elles sont imputables d'abord aux lacunes de notre information concernant des équipes que l'on pourrait, par exemple, imaginer plus cohérentes et durables, mais affectées périodiquement, sur une durée qui nous échappe, d'accidents divers (défaillances d'un collaborateur, besoins exceptionnels, renouvellements du personnel, etc.). Que dire alors des disparates du reste du matériel, beaucoup plus fragmentaire, et des potiers météoriques que l'on voit voyager d'une fournéc à l'autre. Les tableaux XII et XIII montrent à titre d'exemple les relations que l'on peut actuellement établir entre le personnel des deux graffites publiés en 1991 et 1993 (VB 1 et VB 2) et la documentation actuellement connue.

\section{POTIERS ET MODES DE FOURNITURE DE VASES}

Le nombre des potiers différents dans les vingt et un graffites Hermet actuellement les mieux conservés (Mar. groupe I) va de cinq à quinze, étant entendu que trois ou quatre (Mar. 16, $28 ?$ 12, 14) réunissent respectivement onze, treize et quinze collaborateurs, que trois ou quatre (Mar. 1, 7, 9, 15 ?) en comportent dix, que les neuf ou onze derniers se contentent de cinq à sept, au plus huit (Mar. 6), fournisseurs. Des seize textes (gaulois ou latins) les mieux conservés, hors du groupe précédent, trois sont sûrement ou probablement complets (VB 1 et VB 2, Mar. 77 ?) et mettent en cause respectivement onze, dix et sept potiers. Hasard ou détail significatif, les treize autres documents, tous incomplets mais les plus largement préservés du matériel disponible, au moins pour les noms, semblent, compte tenu de leur état, avoir inclus toujours plus de cinq, peut-être plus de six à huit (Mar. 30, 47, 54, 86, 97) collaborateurs, et, dans certains cas, au moins neuf (L-30e), dix (Mar. 53, 76), onze (Mar. 87), douze (L-30d), quatorze (Mar. $74,94)$ potiers. L'état du mobilier, sa dispersion graphique, linguistique, chronologique et topographique ne permettent pas de constituer des groupes significatifs et d'utiliser ces observations comme argument plaidant en faveur d'une modification des conditions de travail. D'autant moins que, dans le texte de la plupart des graffites mutilés, les quantités de vases fournies sont totalement absentes ou largement inutilisables. Du moins peut-on a contrario observer que les comptes les plus anciens (Claude-Néron) et les plus homogènes (graffites Hermet) sont actuellement les seuls à présenter des exemples d'une très forte concentration de la production - ainsi pour cinq potiers Mar. $17: 30100$ vases et Mar. 22 : 33500 vases ; pour six potiers Mar. 5 : plus de 28420 vases ; Mar. 10 : 30350 vases ; Mar. 13 : 27930 vases et Mar. 20 : au moins 30250 vases. 


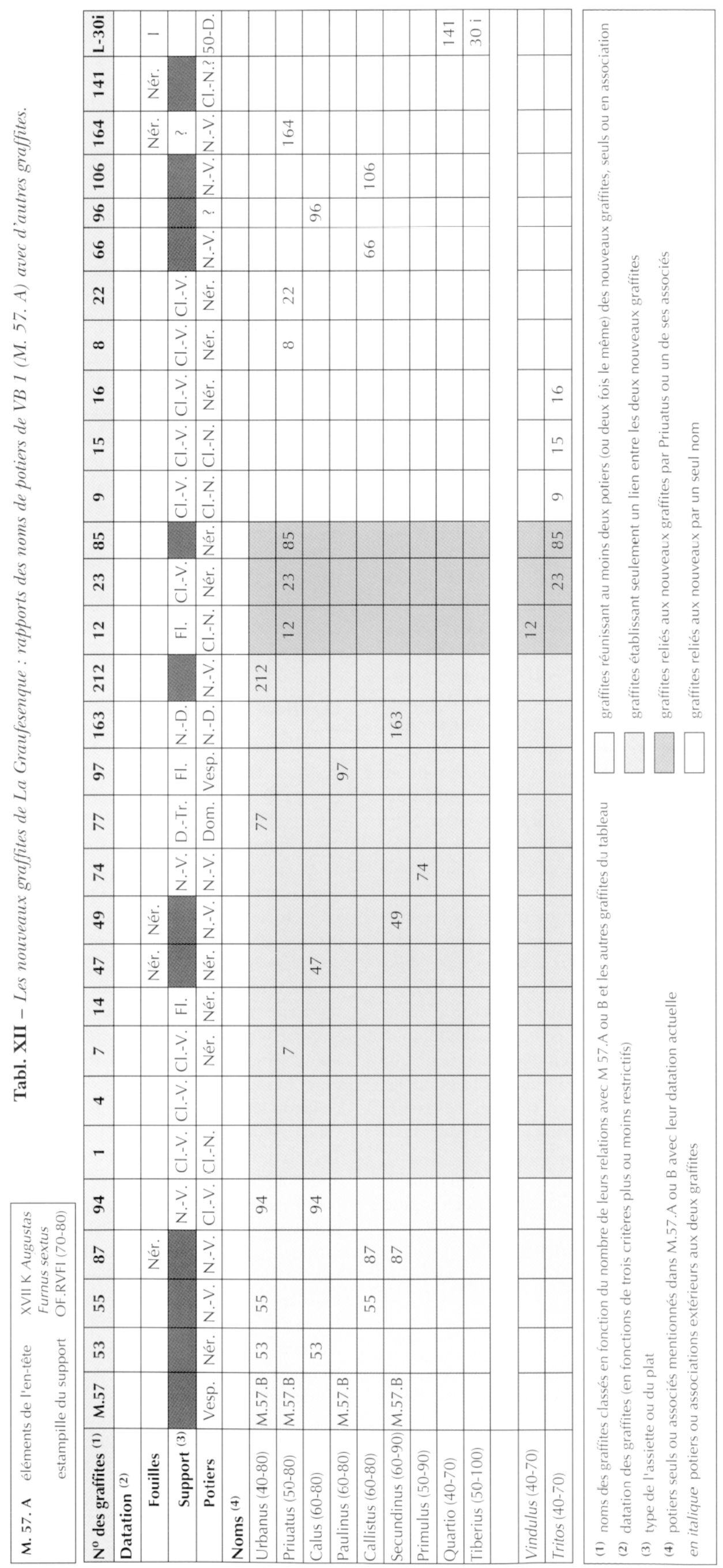




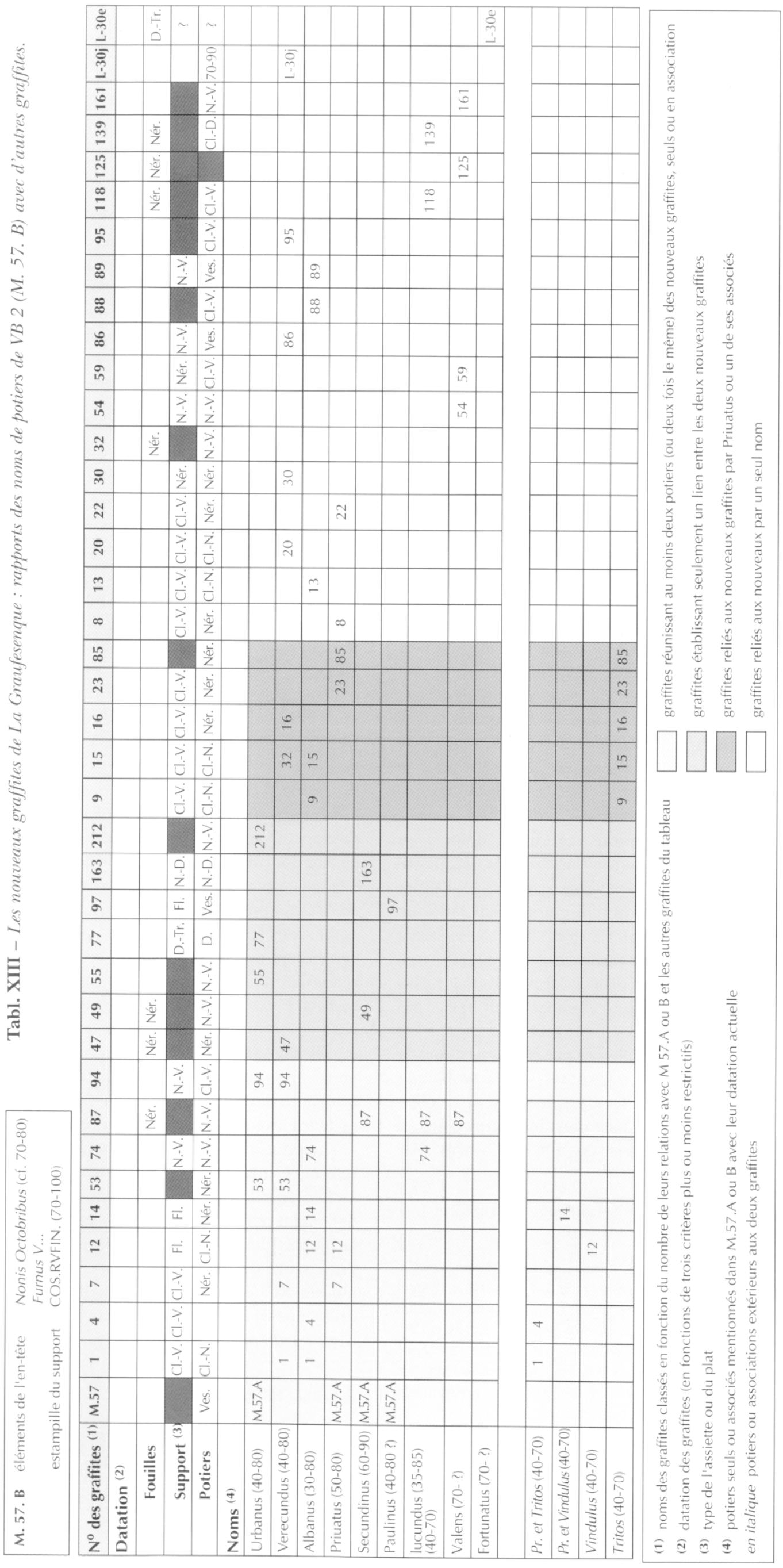


De même, les bordereaux Hermet font apparaître fréquemment un phénomène exceptionnel ailleurs ${ }^{229}$ : la présence dans une dizaine de listes ${ }^{230}$ de potiers réunis par deux ou par trois pour fournir ensemble des lots de vases ${ }^{231}$, en général de plusieurs milliers de pièces (fig. 67). La finalité de cet usage n'cst pas ćvidentc. Cette pratique intervient trop souvent, semble-t-il, pour que l'on imagine une facilité que se donnerait accidentellement le scribe. Peut-être reflète-t-elle, avant cuisson, l'empilement indiscernable dans un hangar de lots insuffisamment différenciés par les fournisseurs (mais pour quelle raison?), ou encore une organisation temporaire du travail. Mais il est actuellement impossible de déterminer un ordre, une évolution chronologique dans la composition de paires ou trios unissant différemment huit individus, qui peuvent, par ailleurs, figurer seuls dans le même ensemble de graffites, voire la même liste (fig. 68, Vindulus). En tout cas aucune estampille à plusieurs éléments nominaux ne correspond jusqu'à présent à aucune de ces associations présumées.

\section{LES VASES}

Les vases enregistrés dans les bordereaux se rangent en une vingtaine de catégories principales, divisées en multiples sousgroupes par des qualificatifs plus ou moins intelligibles et faisant apparemment référence aux particularités morphologiques (a(n)sati "pourvu d'anses "), à un usage spécifique (boletari "destiné [en particulier] aux champignons "), à l'aspect (parfois différentes qualités de rouge: aematina, [mi]niata, bur[ra]]). Ces derniers, d'ailleurs, paraissent pour le moins surprenants compte tenu du fait que la sigillée est globalement rouge et que les vases marbrés (rouges et jaunes), invoqués pour justifier ces précisions, paraissent d'après les découvertes sur sites largement minoritaires, sinon exceptionnels. Cette nomenclature se caractérise par les multiples variantes orthographiques, différant plus ou moins de la forme étymologique classique de certains vocables. Ainsi on rattache au grec parowis, devenu en latin classique paropsis /-idis, une série de graphies plus ou moins proches des formes les plus régulièrement utilisées: paraxidi ${ }^{232} /$ paraxides. Il n'est pas opportun, compte tenu des recherches étymologiques de R. Marichal (1988, p. 80-92) complétées par les suggestions de P.Y. Lambert (2002, p. 113-115), d'exposer ici les problèmes posés par tous les noms de vases. Quelle que soit leur origine, ils apparaissent pour une bonne part dans les textes latins, si utilement publiés par W. Hilgers en 1969. D'autres, par

229. Voir Mar. 75 et $76:$ Vebrullus et Secundanus, Vebrullus et [...]. 230. Mar. 1-7, 9, 10, 14 et 15 .

231. Peut-on domner un sens à la répartition en groupes de ces associations ? Par exemple : Tritos et Privatos (Mar. 1, 2, 3, 4, 5, 6, 10); Tritos et Vindulus (Mar. 13) ; V'indulus et Privatos (Mar. 14) ; Vindulus et Cosoius (Mar. 12) ; Tritos et Felix (Mar. 14) ; Tritos, Deprosagijos et Felix (Mar. 12) ; Felix et Deprosagijos (Mar. 2) ; Felix et Scota (Mar. 1, 3, 5, 7, 10, 15) ; Felix, Scota et Summacos (Mar. 4 et 6) ; Secundus, Albanus, Moretoclatus (Mar. 9). Ces noms peuvent être reliés ou non par les mots de coordination gaulois duci et toni (avant le $3^{\mathrm{c}}$ élément du groupe).

232. Paraps[...] (Mar. 112), parapsides (VB 1), parabsidi (Mar. 154), parasides (Mar. 163) ; paroxe (Mar. 89, 90, 91, 99) font figure d'isolés. exemple broci, cuibalini, fiscos, iulianas, résistent encore à l'analyse.

La question est actuellement moins de savoir à quel vocabulaire ces noms ont été empruntés que d'établir, concrètement, une relation entre les formes classées typologiquement par H. Dragendorff, et les archéologues qui l'ont relayé, et le mobilier cité dans les bordereaux (tabl. XIV). Or il est relativement facile d'identifier certains modèles de base: les catili / catini (catilli / catini, lat.) comme étant ce que nous appelons assiettes et plats, formes plates ouvertes, souvent pourvues d'un petit pied et destinées à présenter les aliments sur la table. Certaines fonctions spécifiques ont en revanche des implications morphologiques très précises, ainsi les atramentari (atramentaria, lat.) ou encriers, les mortari (mortaria, lat.) ou mortiers, et peuvent être mises en rapport avec un nombre très limité de modèles archéologiques produits dans la seconde moitié du $\mathrm{I}^{\mathrm{iT}} \mathrm{s}$. Autre cas de figure : le nom panna a, par chance, été découvert inscrit sur le fond de bols hémisphériques décorés Drag. 37. Produits à partir de 60 environ, ces vases ont peu à peu remplacé des formes carénées en usage depuis le début du siècle et globalement similaires (Bémont, 1995), aussi est-on justifié à reconnaître des Drag. 29, au minimum, dans les pannas enregistrées dans les bordereaux antérieurs à l'apparition des Drag. 37 et, dans les listes plus tardives indistinctement les deux modèles, jusqu'à la disparition des formes carénées vers 80/90.

Toutefois, le détail éventuel de certaines de ces identifications et l'attribution des autres formes sont très hypothétiques, voire impossibles à déterminer à partir des seuls graffites de cuissons. Les inventaires, en effet, prennent en compte des noms dont l'étymologie n'est pas toujours claire et dont l'usage local dans un milieu professionnel relève apparemment (comme il advient fréquemment dans d'autres langues) de conventions qui, dans ce cas, nous sont autrement inconnues. Les adjectifs qui les qualifient restent, sauf exception (ansati, sesilis...), obscurs. Les tailles ne peuvent avoir de sens que comparées à des statistiques significatives et impliquent également une certaine approximation, puisque l'unité de référence n'est pas, comme l'est pour nous le mètre-étalon, respectée par chacun avec rigueur. Enfin, les quantités ne permettent que de distinguer quelques formes très répandues et très largement attestées. Le recoupement de ces paramètres peut cependant autoriser quelques propositions, à condition évidemment que les périodes de fabrication des types proposés incluent les fourchettes de datation des bordereaux.

Les graffites ne présentent actuellement pour nous aucune référence intelligible aux types ou profils distingués par les archéologues, et les textes anciens réunis par Hilgers font essentiellement référence à l'usage de ces objets, sans en définir, dans la plupart des cas, la forme précise. En prenant comme base l'inventaire des formes les plus citées et commentées dans le tableau XIV établi à partir du tableau dressé par R. Marichal (1988, p. 81 et 82 ), il me paraît possible, avec toutes ces réserves, de proposer des observations sur quelques catégories.

\section{ACITABLI ET PARAXIDI}

Les premiers sont, par leur nom, des vases à vinaigre (acelabulum en latin classique) utilisés comme petites mesures de 
Tabl. XIV - Vases des bordereaux de La Craufesenque ayant donné lieu à des commentaires.

\begin{tabular}{|c|c|c|c|c|c|c|c|c|c|c|c|c|c|c|}
\hline \multirow{2}{*}{ Noms } & \multicolumn{2}{|c|}{ Hilgers } & \multirow{2}{*}{$\begin{array}{c}\text { Marichal } \\
\text { définitions } \\
\text { des vases }\end{array}$} & \multirow{2}{*}{ Uxsed } & \multirow{2}{*}{$\begin{array}{c}\text { Sans } \\
\text { dimensions }\end{array}$} & \multicolumn{5}{|c|}{ Mesures $(\mathrm{en} \mathrm{cm})$} & \multicolumn{3}{|c|}{ Formes } & \multirow{2}{*}{$\begin{array}{l}\text { Types? } \\
\text { (Marichal) }\end{array}$} \\
\hline & références & $\begin{array}{l}\text { définitions } \\
\text { des vases }\end{array}$ & & & & $\begin{array}{c}\text { pedales } \\
29,6\end{array}$ & $\begin{array}{c}\text { bessales } \\
19,7\end{array}$ & $\begin{array}{c}\text { semiped. } \\
14,8\end{array}$ & $\begin{array}{c}\text { triant. } \\
9,8\end{array}$ & $\begin{array}{c}\text { sextant. } \\
4,9\end{array}$ & plats & creux & indét. & \\
\hline Acitabli & p. 33,91 & à vinaigre & à vinaigre & & 210750 & & & & & & & $x$ & & Dr. $24 / 25,27$ \\
\hline VB 1 et 2 & & & & & 9300 & & & & & & & & & \\
\hline Atramatari & p. 39,112 & encrier & encrier & & 1505 & & & & & & & $x$ & & Her. 18 \\
\hline$V B 1$ et 2 & & & & & 1150 & & & & & & & & & \\
\hline \multirow[t]{2}{*}{ Boletari } & p. 121 & à champignons? & à champignons & & 600 & & & & & & $x$ & $x$ & $?$ & \\
\hline & & à gâteaux & & & & & & & & & & & & \\
\hline Broci & p. 122 & $?$ & $?$ & & 30 & & & & & & & & $x$ & \\
\hline Calices (VB 1) & p. 44,130 & coupe à pied & & & 1200 & & & & & & & $x$ & & \\
\hline Camellas & p. 135 & à mélanger & plats apodes & & 300 & & & & & & $x$ & & & Her. 12 \\
\hline Canastri & p. 135 & à miel, huile? & corbeilles? & & & 695 & 3960 & & 3740 & & & $?$ & $x$ & Dr. 22? \\
\hline$V B 1$ et 2 ? & & & & & & 50 & 1050 & & 1200 & & & & & \\
\hline \multirow[t]{2}{*}{ Catili } & p. 142 & assiettes & assiettes & & 175058 & 150 & 300 & 200 & 135 & & $x$ & & & plusieurs \\
\hline & & & & $x$ & 8350 & 55 & 350 & & 660 & & & & & \\
\hline VB 1 et 2 & & & & & 14150 & & & & & & & & & \\
\hline dont catili dupros. & & & & & 2250 & & & & & & & & $x$ & \\
\hline VB 2 (bipros) & & & & $x$ & $>500$ & & & & & & & & & \\
\hline dont catili ses. & & & ass. apodes & $x$ & & & & & & & & & & Her. 2 \\
\hline Catini & p. 48,142 & plats (creux ?) & plats & & & 160 & 2390 & & 1625 & & $x$ & & & plusieurs \\
\hline Cuibalini & cf. p. 162 & erreur & $?$ & & 440 & & & & & & & & $x$ & \\
\hline Fiscos? & cf. p. 183 ? & & $?$ & & & 55 & 450 & & & & & & $x$ & \\
\hline Inbra(c)tari & p. 197 & pour la cuisine & récipients creux & & 100 & & 415 & & & & & $x ?$ & & \\
\hline VB 1 & & & & & 200 & & & & & & & & & \\
\hline Iulianas & p. 199 & $?$ & $?$ & & 740 & & & & & & & & $?$ & \\
\hline Licuias & p. 214 & $?$ & "creusets" & & 100670 & & 870 & & 1330 & & & $x$ & & Dr. 33 \\
\hline Magedes & p. 216 & grands plats & plats creux & & & & 150 & & 150 & & & $x$ & & Her. 19? \\
\hline \multirow[t]{2}{*}{ Mortari } & p. 68,225 & mortiers & mortiers & & 300 & 708 & 4645 & & 4950 & & & $x$ & & Ritt. 12 \\
\hline & & & & $x$ & 1870 & & 50 & & 200 & & & $x$ & & \\
\hline Pannas & p. 237 & bols & bols & & 13015 & 122 & 25640 & 3000 & 430 & & & $x$ & & Dr. 29,37 \\
\hline$V B 1$ et 2 & & & & & 4300 & & 400 & & $>500$ & & & & & \\
\hline Paraxidi & p. 33,238 & grands acitabli & grands acitabli & & 157650 & & & & & & & $x$ & & cf. $24 / 25,27$ \\
\hline$V B 1$ et 2 & & & & & 9750 & & & & & & & & & \\
\hline Pultari & p. 264 & à col étroit & à bouillie & & 1400 & & & & & & & & $x$ & \\
\hline$V B 1$ et 2 & & & & & 1750 & & & & & & & & & \\
\hline Salaria & & & à sel & & & & & & & & & & $x$ & \\
\hline Tisanares & p. 289 & à tisane d'orge & & & 800 & & & & & & & & $x$ & \\
\hline \multirow[t]{2}{*}{\begin{tabular}{|l|} 
Vinari \\
\end{tabular}} & p. 297 & lagènes? & $?$ & & 3415 & 425 & & & & & & $x$ & & \\
\hline & & & & $x$ & 475 & & & & & & & & & \\
\hline$V B 1$ et 2 & & & & & 550 & & & & & & & & & \\
\hline
\end{tabular}

vases provenant de VB 1 et 2 absence d'informations
Dr. typologie de Dragendorff

Her. typologie d'Hermet (1934)
VB 1 Vernhet, Bémont, 1990-1991

VB 2 Bémont, Vernhet, 1992-1993 
capacité (Hilgers, 1969, p. 91 et 92) ; les paraxidi sont considérés comme la taille au-dessus des acitabli (acetabulum maius, voir Hilgers, 1969, p. 239). Compte tenu de leur fréquence, le choix est possible entre Drag. 24/25 (coupe hémisphérique à bord vertical) et Drag. 27 (coupe tronconique à panse étranglćc), l'unc ct l'autre issues de modèles italiques et produites en grandes quantités (fig. 69). À mon sens, l'identification pourrait être envisagée un peu différemment en prenant en compte des données chronologiques et les graphiques métrologiques établis à partir de l'abondant matériel de la fosse néronienne de Gallicanus ${ }^{23.3}$ (Bémont, 1987, p. 336 ; Bémont et al., 1987, p. 20) : les deux formes comportent, chacune, deux modules principaux (fig. 70) correspondant à des nuages quasi superposables (diamètres $7 / 9 \mathrm{~cm}$ et $11 / 13 \mathrm{~cm}$ ). Il paraît concevable, en l'absence d'informations morphologiques, que les deux types représentent jusque vers 65 (période d'extinction des Drag. 24/25), l'un ou l'autre, ou ensemble, pour la petite taille, les acetabli, pour la grande, les paraxidi ${ }^{234}$. Les graffites plus tardifs ne concerneraient plus cependant que les Drag. 27 (à moins d'affecter au même office des tasses des services flaviens).

\section{CATILI ET CATINI}

En l'absence de précisions intelligibles l'hésitation est possible entre les formes plates Dr. 17b, Dr. 21, Ritt. 1, Dr. 16, Dr. 15 et $15 / 17$, Dr. $18^{233}$, qui diffèrent par le profil du bord, mais seuls les trois derniers modèles subsistent à partir du règne de Néron, les deux derniers, à partir de Domitien. De même les assiettes dites sessiles (apodes) se limitent à deux types, l'un en calotte (Hermet 2/12c), l'autre cylindrique (Dr. 22) ; le premier survit au second, très rare dès Vespasien. À partir de Domitien, le type Drag. 18 évolue vers un profil plus profond (Drag. 18/31) et parallèlement sont créés, entre cnviron $60 \mathrm{et}$ 90, six modèles flaviens d'assiettes: A à F (Vernhet, 1976), la plupart à marli et/ou fond creux, qui autorisent de nouvelles hésitations pour les graffites les plus tardifs (fig. 71).

Les modules distingués par les graffites dans l'abondant groupe des calili sont au nombre de quatre (pied, 2/3, 1/2, $1 / 3$, soit théoriquement entre $29,7 \mathrm{~cm}$ et environ $10 \mathrm{~cm}$ ). Or les assiettes de la fosse de Gallicanus que nous avons traitées révèlent aussi quatre paliers plus ou moins nettement séparés : l'un autour de $13 / 14 \mathrm{~cm}$, l'autre autour de $17 / 18 \mathrm{~cm}$, le troisième vers $25 \mathrm{~cm}$, le dernier entre $30 \mathrm{ct} 32 \mathrm{~cm}$ (fig. 70). Ce qui montre le caractère à la fois approximatif et conventionnel de la nomenclature des graffites (à moins, et encore, d'admettre un pied différent du pied "gaulois"). Les services flaviens, en revanche, selon les observations d'A. Vernhet (1976, passim) présentent selon le type un nombre variable de

233. Dépotoir homogène contenant environ 9000 pièces contemporaines. Les graffites métrologiques de corrélation mettent en cause plus de 400 vases pour les Drag. 27, plus de 1500 pour les Drag. 24/25.

234. Ce cas tend à étayer l'hypothèse proposée voilà quelques annćes d'une nomenclature impliquant (en l'absence de mesures) à la fois forme et taille (Bémont, 1987, p. 342).

235. Il faut souligner cependant qu'elles ne sont pas toutes produites en quantités aussi importantes et il y aurait lieu de revoir leurs modules.

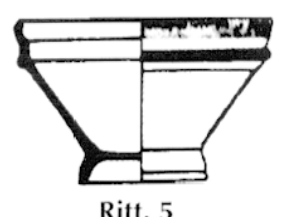

Ritt. 5

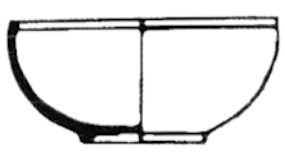

Ritt. 8

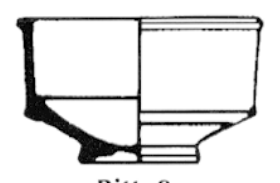

Ritt. 9

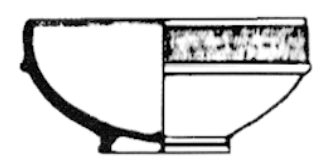

Drag. 24/25

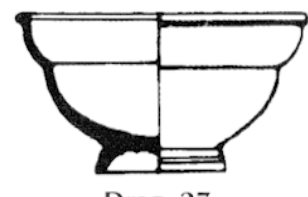

Drag. 27

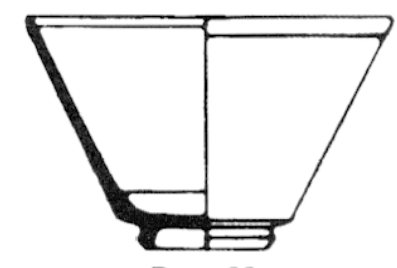

Drag. 33
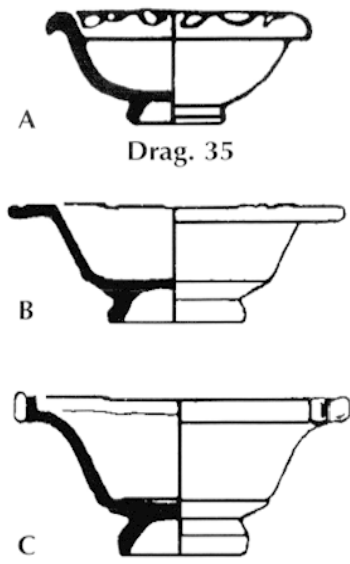

Drag. 46

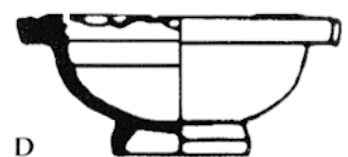

Ritt. 14
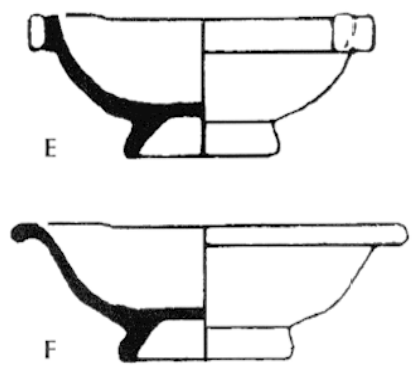

$\mathrm{F}$
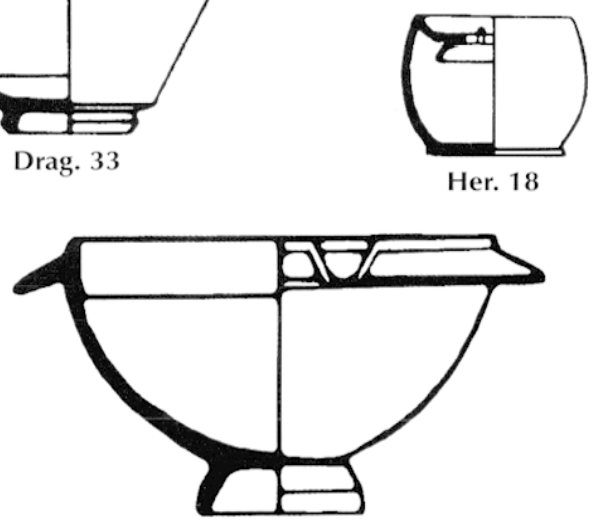

Ritt. 12

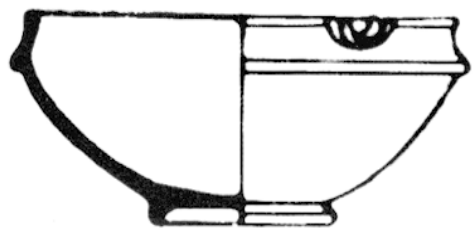

Her. 23

Fig. 69 - La Craufesenque : principales formes creuses sans décors lrègne de Claude-début du ir's.]. 


\section{FORME 024}

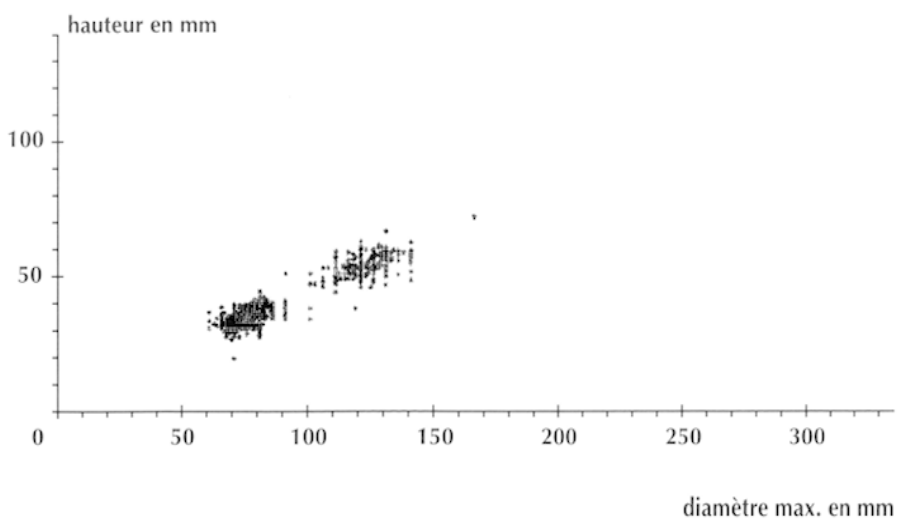

FORME 027

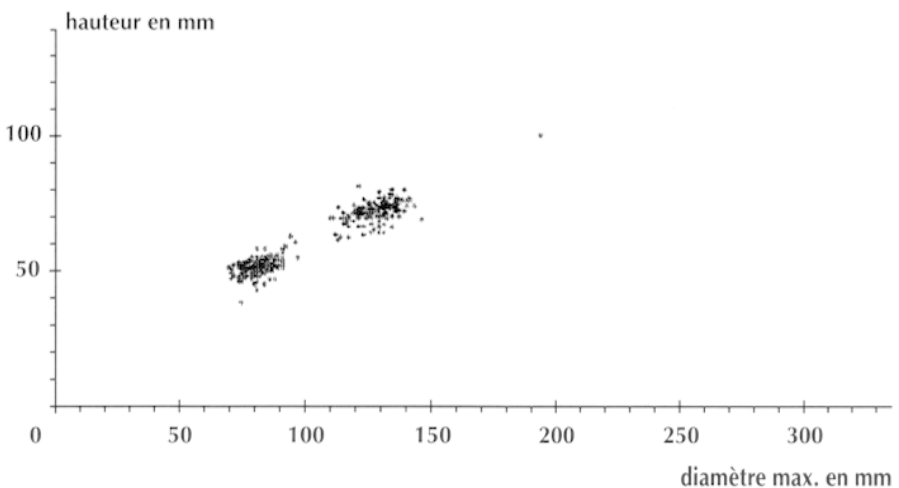

FORME 018

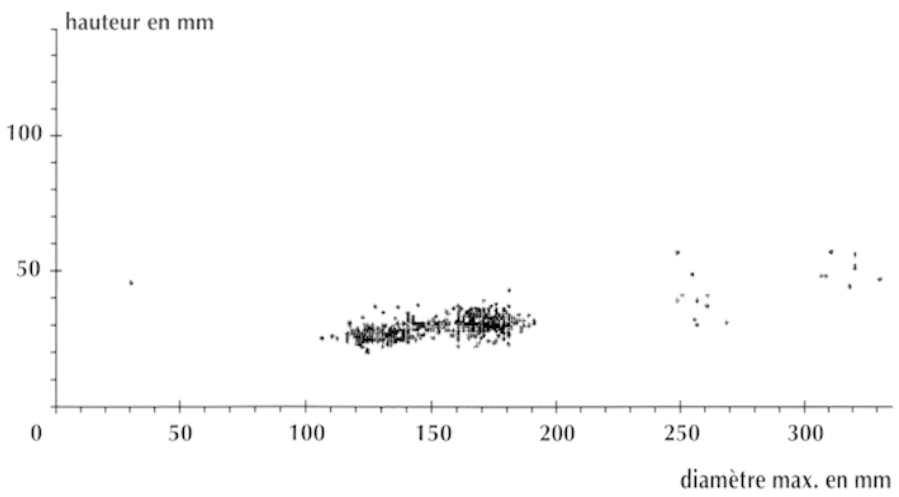

Fig. 70 - La Graufesenque, fosse de Gallicanus [55-60] : exemples de graphiques de corrélation des petits bols Drag. 24/25 et 27, des assielles Drag. 18 (traitement H. Leredde, CNRS).

modules: deux (service $C$ ?), trois $(B, F)$, quatre $(A, D)$, voire cinq (E) compris dans l'ensemble entre 9 et $29 \mathrm{~cm}$, c'està-dire plus proches de la fourchette globale des graffites. Outre les variations du nombre des modules d'un service à l'autre et l'apparition (exclusive?) de toutes petites assiettes D et $\mathrm{E}$ (vers $9 \mathrm{~cm}$ ), et de grandes tailles dans le service A, les paliers des tailles moyennes les plus courants ne correspondent pas non plus, d'après le matériel de fouille, aux fractions théoriques du pied gaulois.
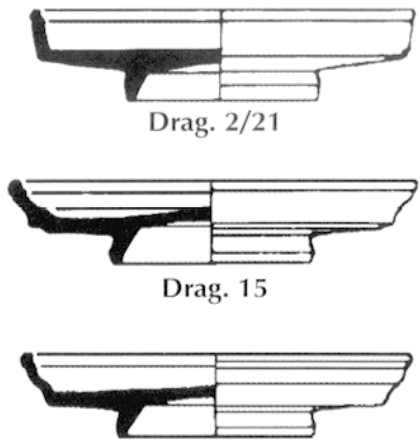

Drag. 16

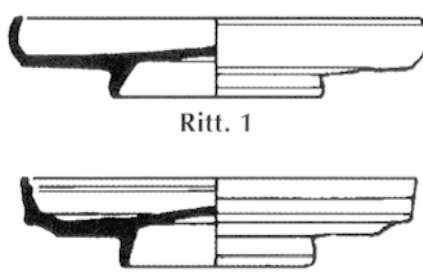

Drag. 15/17

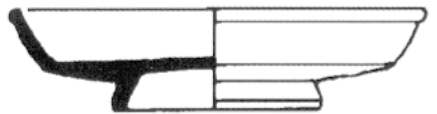

Drag. 18/31

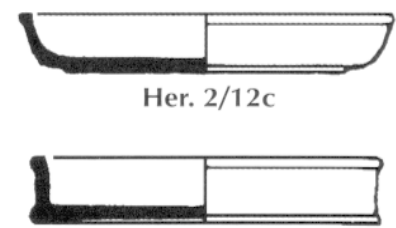

Drag. $4 / 22$
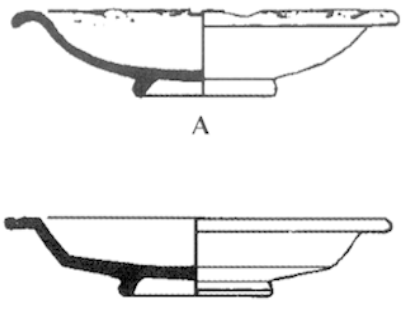

B
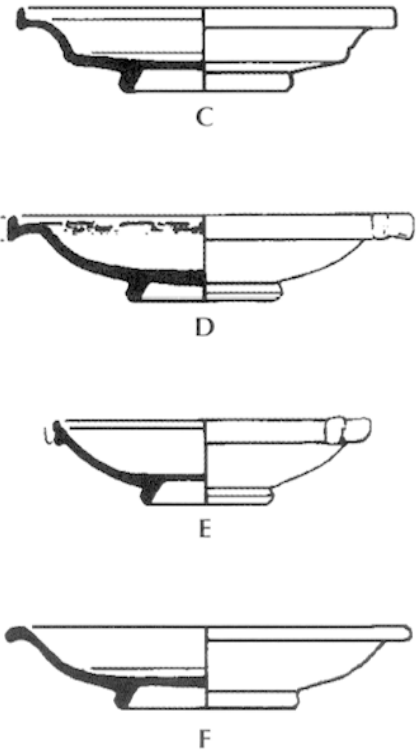

Fig. 71 - La Graufesenque : principales formes plates [règne de Claude-début du Ir's.].

Une fois envisagé le caractère conventionnel de la nomenclature des tailles, deux problèmes principaux sont posés. D'abord 175000 " assiettes " sans mesures devraient, semblet-il, compte tenu du mobilier recensé le plus souvent dans les fouilles se concentrer principalement entre $12 \mathrm{et} 19 \mathrm{~cm}$; mais la preuve en reste à faire. Par ailleurs, la différence entre catili et catini n'est pas évidente. Les catini, très peu nombreux dans les bordereaux (Marichal, 1988, p. 85 et 86), présentent trois des paliers de tailles des catili (y compris le plus petit). La notion du catinus (ou plat), conçu le plus souvent comme une " grande assiette ", n'est donc pas recevable et on ne peut invoquer non plus à l'intérieur des graffites une différence chronologique dans l'emploi des deux vocables. Cette indifférenciation ne peut-elle être imputable soit simplement à une négligence du langage provincial et à une préférence de la majorité des potiers ou scribes pour l'emploi de catili, soit à une évolution locale (?) du sens, en supposant que catini et catili diffèrent morphologiquement et correspondent à deux types ou groupes de types? 


\section{LICUIAS}

Ce modèle, attesté à plus de 100000 exemplaires, a été identifié hypothétiquement avec le type Drag. 33, coupe tronconique à bord lisse, proche d'un modèle italique augustéen (Consp. 7) et promise à un long avenir. Bien que moins abondante que d'autres, elle est assez bien attestée à La Graufesenque (fig. 69). Les modules signalés dans les comptes et relativement peu représentés correspondent aux bessales et aux triantales. On peut se demander si une part notable des quelque 100000 pièces sans dimensions n'appartenait pas à la taille intermédiaire (semipedales, $13 / 16 \mathrm{~cm}$ ) presque seule représentée parmi les 240 échantillons utilisables de la fosse de Gallicanus, alors qu'un seul vase illustre le grand modèle $(19 \mathrm{~cm})$. Recourir au type Ritt. 5 comme triantales était difficile, compte tenu de son extinction entre 40 et 60 (Marichal, 1988, p. 88). Est-ce nécessaire ? On peut assurer que, bien qu'assez peu nombreux, les petits Drag. 33 n'étaient pas inconnus durant la période concernée ${ }^{236}$.

\section{MORTARI}

Cette forme, identifiée avec une certaine vraisemblance avec le type Ritt. 12 (fig. 69) et attestée par des pedales, des bessales, des triantales et des exemplaires sans dimensions, pose lors de la confrontation des bordereaux et du matériel de la fosse deux questions. La présence hypothétique dans le dépotoir de trois nuages très clairsemés : l'un autour de $25 \mathrm{~cm}$, l'autre entre $15 \mathrm{et}$ $18 \mathrm{~cm}$, le troisième au-dessous de $15 \mathrm{~cm}$ suppose probablement une certaine tolérance dans la nomenclature des tailles supérieures représentées dans cet ensemble. Autre problème, celui des triantales: quelques échantillons de la fosse sont compris entre 10 et $14 \mathrm{~cm}$. Représentent-ils le plus petit module ? La rareté, tout à fait justifiable, de cette forme d'usage collectif à La Graufesenque permet surtout d'hésiter sur les limites effectives des tailles.

\section{PANNAS}

La dernière catégorie largement commentée, car elle est elle aussi facilement identifiable, a soulevé une question : celle du petit module. Bien représentées entre environ 14 et $25 \mathrm{~cm}$, beaucoup moins entre 25 et $29 \mathrm{~cm}$ et avec des pics autour de 16 et $21 \mathrm{~cm}$, les formes carénées Drag. 29 de la fosse de Gallicanus présentent par leur répartition de très grandes ressemblances avec les diagrammes collectifs, englobant des bols décorés Drag. 29 et 37, qu'ont dressés A. Mees (1995, p. 27) et, pour Cala Culip, X. Nieto (2001, p. 40). En revanche, les triantales,

236. Par exemple d'après une estimation fondée sur la taille des pieds et leur corrélation avec le grand diamètre des vases, les pièces de 13-16 cm (pied : environ $50-55 \mathrm{~mm}$ ) devaient être très nombreuses à Glanum parmi les exemplaires signés identifiés (Bémont, 1976) ; les grands échantillons de ce même type sont attestés par quelques exemplaires (voir Cantus, Catus, Cosius Rufinus, Felix, Fesius, Gallicanus, Lepidus, Mommo, Paullus, Rusticus, Secundus, Taurrus, Tertius, Vilulus: pied entre 58 et 65 ? mm), les petits modèles restent rares (voir Coius, Mommo, Patricius, Quintanus, L. S. Sabinus: Tertius Masculus, Tornus, Vrituarus? : pied de 45 à $48 \mathrm{~mm}$ ). attestés actuellement dans des graffites de la période ClaudeNéron, semblent dans les trois cas faire totalement défaut. R. Marichal (1988, p. 89) propose d'y substituer des petits bols lisses hémisphériques, voir Ritt. 8 (fig. 69). Leurs tailles, concentrées entre 6,5 et $9 \mathrm{~cm}$ et moins nettement entre 11 et $14 \mathrm{~cm}$, pourraient à la rigueur convenir, mais leur production est brève (environ 25-60) et surtout rien ne prouve que les potiers aient assimilé formes lisses et formes décorées pour les besoins d'une typologie. Ne pourrait-on donc envisager aussi pour ce poste la candidature des formes Her. 9 : petits bols décorés à parois verticales (fig. 63) produits entre le début ou le cours du règne de Claude et environ 75 ?

\section{RÉDACTION DES BORDEREAUX ET CAS PARTICULIERS}

Comme l'a très bien montré R. Marichal (1988, p. 101-106), ces mémoires établis à l'occasion de la cuisson des fournées n'étaient pas rédigés à la volée au cours des opérations de chargement, même si on a pu supposer que l'ordre observé correspondait grossièrement aux dispositions prises dans le four: les grands vases peu nombreux d'abord, les petits par milliers après. Il reste pourtant à prouver expérimentalement (on l'a trop souvent oublié) que le chargement des piles ne posait pas des problèmes différents de poids relatifs et d'équilibre de la chaleur selon qu'il s'agissait de colonnes très denses de vases identiques et de tailles assez modestes, d'emboîtements plus aérés de bols gigognes décorés, ou de pièces isolées (encriers, gourdes, lagènes), et qu'il n'imposait pas à l'intérieur du four une organisation différente de celle des bordereaux. Sans s'attarder à ces questions encore non résolues (mais actuellement prises en compte par des artisans potiers), R. Marichal a montré, sur la base de vraisemblances internes, que les bordereaux étaient des copies rédigées le plus souvent par un seul scribe à des fins comptables et non l'enregistrement sur le vif des opérations de chargement. Ce travail devait se dérouler hors de l'agitation du four, à partir de notes prises par lui ou de bordereaux partiels (établis à l'occasion d'une livraison?), tels qu'on en trouve plusieurs parmi les textes conservés (Mar. 53 ? 77, 82, 90, 163-171). Ces derniers, également écrits sur assiettes crues, mais beaucoup plus réduits, concernent actuellement soit un seul potier et la fourniture de quelques lots de vases (par exemple Mar. 90, 163), soit un petit nombre de potiers n'occupant qu'une petite fraction de la surface de l'assiette (Mar. 77), ou encore une liste de vases sans autres références que le support signé (Mar. 165). Le travail de récapitulation d'après des originaux éventuellement écrits par d'autres scribes présente l'avantage d'expliquer des disparates orthographiques à l'intérieur de certains graffites de fournées. La présentation, au moins partielle, dans certains cas des lots par potiers, plutôt que strictement par types et tailles de vases, et le relatif désordre qu'elle génère (par exemple Mar. 30, 54, 76, où plusieurs catégories de vases sont mêlées) pourraient s'expliquer par ces copies. À moins encore qu'il ne s'agisse parfois d'une contribution survenue (ou seulement enregistrée) après coup. Ainsi Mar. 85 mentionne en fin de graffite Lousios comme fournisseur de paraxidi MDL, mortari CCC, (catili) duprosopi M, acitabli 


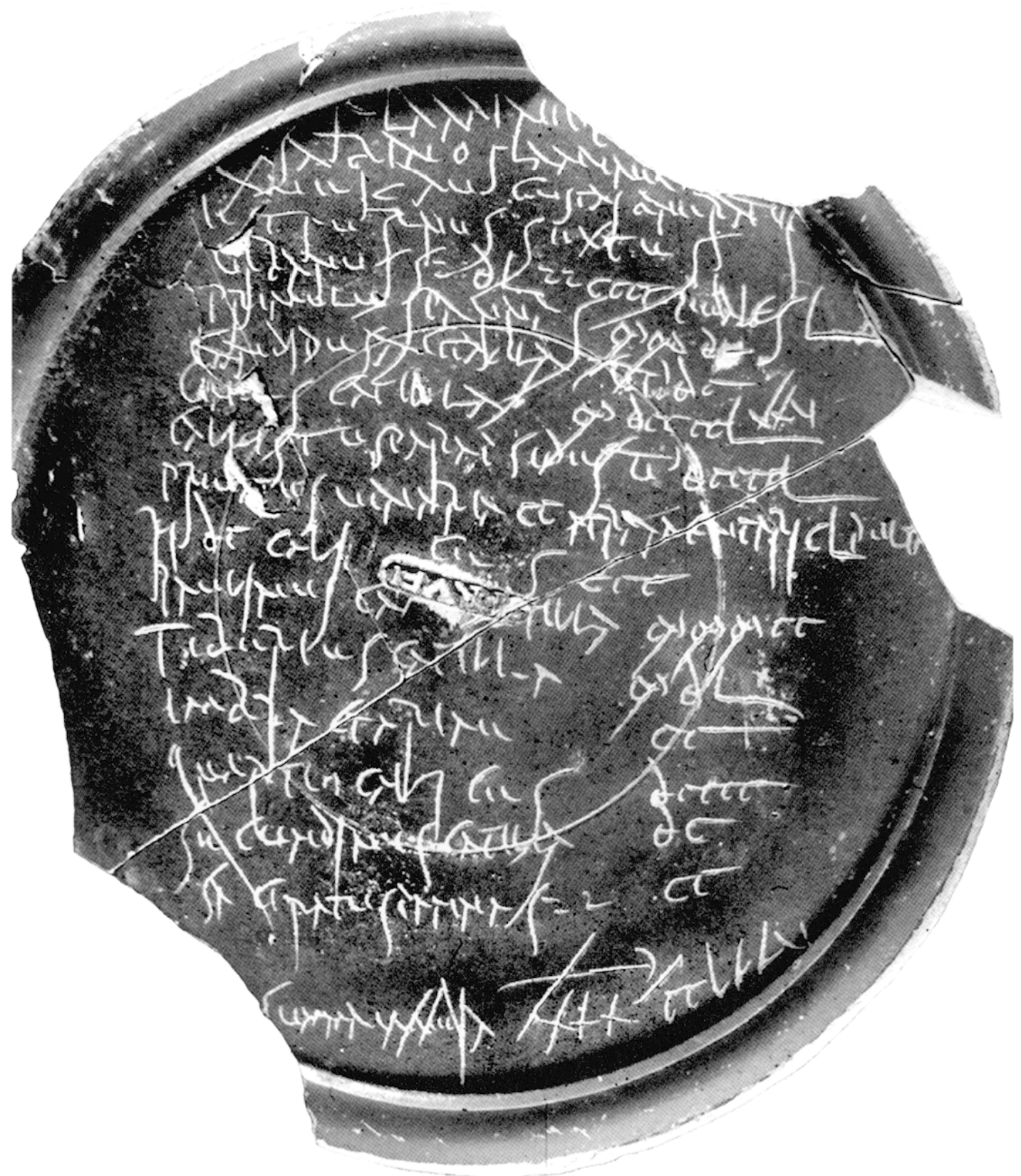

Fig. 72 - La Graufesenque : graffite "latin" VB I [Vespasien]; estampille: OF RVFI (cliché A. Vernhet, CNRS).

IIXD : types par ailleurs répartis, et dans un ordre différent, sur l'ensemble du graffite.

Il semble donc, d'après des exemples simples et divers, que nous saisissions, presque au quotidien, le déroulement d'un travail d'enregistrement et de récapitulation avec ses imperfections, ajouts éventuels et corrections (mention biffée et rectifiée: Mar. 66). Encore l'état des assiettes ne permet-il pas d'évaluer exactement le contenu et l'intérêt des textes complémentaires inscrits parfois sur l'autre face du support et dont il ne reste en général que de petits fragments. Autre cas notable (fig. 72) : un exemple actuellement unique (VB 1) de graffite non mutilé portant une summa uxxedia de 30355 , alors que le total des vases enregistrés atteint 19925 , suggère une première/autre page aujourd'hui perdue ${ }^{237}$. Quoi que suppose G. Fülle (2000, p. 87-89) nous ne disposons pas actuellement d'un matériel exactement comparable qui permette de discuter ce texte sur des bases solides. Toutefois le document, bien qu'entier, porte un compte incomplet et il n'est pas possible d'imaginer qu'une comptabilité sérieusement tenue et

237. Ia présence en haut de la liste d'une série de lots par tailles, fournis par Crbanus et dépourvus du nom des vases, pourrait éventuellement donner un argument. Mais il existe maintenant un autre cas comparable avec le même Crbanus (VB 2), dans un graffite plus étoffé (26 930 vases), sans somme. Urbanus serait-il dans ces livraisons le spécialiste d'une forme? 
conservée pendant un certain temps se soit privée systématiquement du souvenir de la contribution d'un participant, fût-ce le maître-d'œuvre/maître-fournier. Imaginer l'enregistrement à part de comptes " anonymes " (ici 10000 pièces) crée une complication et ne résout pas la question du support matériel : comment se présentaient ces archives séparées, sinon sans doute sur des assiettes? Ainsi, quelles que soient la nature de cette autre "page " et la place qu'elle occupait, son existence est obligatoire. D'autre part, le titre figurant en haut de notre bordereau (et jugé illogique par G. Fülle sur une " deuxième page ") peut bien en fait, où qu'il figure, se justifier - comme la somme, en bas - par la nécessité d'identifier facilement l'un par rapport à l'autre deux fragments d'un même compte, qu'il n'était évidemment pas question d'agrafer!

Ces textes en tout cas montrent, par leur rareté et les hypothèses qu'ils suscitent, combien cette documentation est lacunaire et inégalement répartie. Aussi est-il dangereux de considérer un échantillon aléatoire et trop profondément mutilé comme représentatif de la forme et du contenu de tous les comptes. Nous disposons actuellement de documents matériellement entiers, et pouvant correspondre à une fournée, et de quelques échantillons que leur disposition amène à considérer comme volontairement partiels ou incomplets. Et l'on observe déjà des différences entre des échantillons comparables (présence/absence de summa). Mais nous ne pouvons prétendre que d'autres types d'archives ou de notes n'existaient pas. Nous ne pouvons non plus, compte tenu du déséquilibre entre la qualité des graffites Hermet et celle du reste des témoins, soutenir que les modes de collaboration entre potiers ont été rigourcusement identiques d'un bout à l'autre de la production.

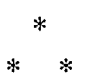

\section{L'ÉCRITURE À LA GRAUFESENQUE : SES IMPLICATIONS, SES LIMITES}

\section{L'ALPHABÉTISATION}

L'examen d'une quantité notable de textes provenant des ateliers de La Graufesenque met en évidence plus qu'ailleurs, du fait de la diversité locale des modes de signature, comme du nombre et de la variété des textes découverts, l'alphabétisation d'une part du personnel. Les producteurs de sceaux témoignent, outre d'un talent certain pour la gravure, d'une aptitude à lire les mots et à les manipuler (abréviations, ligatures) à l'endroit et à l'envers. Par ailleurs, si les auteurs (décorateurs/fabricants ?) de signatures inscrites dans les moules ${ }^{238}$ limitent au maximum leur travail de rédaction, du moins l'aisance de leurs ductus tend-elle le plus souvent à suggérer que

238. I a question est la même pour les poinçons utilisés pour la décoration des moules et parfois signés. Leur nombre actuellement très faible ne modifie pas sensiblement la liste générale des signataires. l'écriture leur était coutumière. Il en va de même a fortiori pour les rédacteurs des comptes.

Il apparaît toutefois qu'il est difficile d'évaluer sans arbitraire l'importance relative, à l'intérieur des fabriques, de cette population, "lettrée " ès qualité. Car on ne sait lesquelles de ces fonctions pouvaient être concentrées entre les mains de spécialistes, ou si ces compétences étaient largement partagées et associées selon les opportunités à d'autres responsabilités dans les officines. Il va de soi que le nombre des autres employés des ateliers obligés de lire ces documents, ou capables de le faire, est encore plus incertain.

Il est remarquable cependant que l'usage des marques pseudo-épigraphiques attribué hypothétiquement à des analphabètes (voir supra, p. 104), sans être négligeable, paraît à La Graufesenque limité et sujet à la critique. À titre indicatif, Hermet dénombrait globalement vingt échantillons différents, faits pour l'essentiel de hastes verticales ou obliques, et qu'il ne lisait pas (Hermet, 1934, pl. 113). Nous avons compté dans la fosse de Gallicanus (datée vers 60 ) à côté de quatre-vingt-onze noms de potiers identifiables par une ou plusieurs estampilles différentes, cinq marques, actuellement indéchiffrables, composées de hastes, ou de hastes et de signes arrondis, et utilisées pour certaines sur plusieurs dizaines de vases. A. Mees signale sur les moules décorés deux signatures ne comportant pas de noms, l'une de forme numérique (XII) et dont la signification n'est pas claire, l'autre composée de haste et demicercles et datable entre 65 et 85 (Mees, 1995, p. 100-101). Si les dénombrements précis font encore défaut, les présumées " nébuleuses " paraissent d'ordinaire aux fouilleurs beaucoup plus nombreuses à la fin du $\mathrm{I}^{\mathrm{er}} \mathrm{s}$. En fait, l'expertise de la fosse de Gallicanus avec la collaboration d'archéologues de l'équipe de B. Hartley (Leeds) et l'inventaire des marques que j’ai mené voilà quelques années dans toute la Provence m'ont montré que le nombre des marques illisibles diminuait considérablement en fonction du mobilier épigraphique de comparaison dont on pouvait disposer. Il paraît évident à l'heure actuelle, comme le confirme A. Vernhet, que la multiplication des marques illisibles constatée en général sur les vases lisses, dans le cours de la période flavienne et plus tard, est imputable pour une grande part à la dégradation des méthodes de travail plutôt qu'au progrès de l'illettrisme. Elle résulte bien souvent de l'impression, parfois hâtive, de marques épigraphiques de mauvaise qualité : amputées aux extrémités, érodées en haut et en bas, aux tracés faibles, ou aux hastes et courbes fusiformes, non jointives. Et elle doit être mise en rapport avec une perte générale de qualité (emploi de sceaux usés, gravures originelles moins soignées), qu’on reconnaît à la même époque dans l'ensemble de la production: lourdeur des vases, défauts de l'engobage, irrégularité des cuissons et moulages mal faits (pour les pièces décorées). En l'occurrence il advient très souvent que la confrontation avec des estampilles comparables, mais moins dégradées, donne la clef de la lecture et permette l'attribution du vase. Aussi y aurait-il lieu de reprendre la critique des signatures illisibles (présumées pscudo-épigraphiques) et d'en préciser les critères d'identification, avant d'en mesurer les variations numériques et d'en analyser la signification sociologique. 


\section{QUELQUES DONNÉES LINGUISTIQUES}

À la différence des objets finis destinés à la commercialisation et signés régulièrement en latin, l'un des aspects remarquables des graffites est le mélange linguistique qu'ils révèlent : l'usage concurrent, au moins jusqu'aux Flaviens, d'en-têtes et d'éléments lexicographiques romains ou gaulois, et d'une onomastique souvent mixte durant une même période, parfois dans le même document. Nous entendons par là, tant la diversité des désinences attribuées à un même nom que l'existence possible de traductions d'une langue dans l'autre. Il est remarquable par ailleurs que les noms propres enregistrés sur ces listes se réduisent jusqu'à présent à des idionymes à un seul élément, notable aussi que les estampilles à tria nomina tendent le plus souvent, dès la fin du $\mathrm{I}^{\mathrm{cr}}$ et au début du $\mathrm{II}^{\circ} \mathrm{s}$., à sacrifier le gentilice au bénéfice du cognomen. Aussi est-il tentant, sinon prouvé, de supposer que l'usage quotidien privilégiait l'usage du nom personnel unique, habituel dans la langue gauloise.

La nomenclature des vases, elle, était pour une grande part commune aux différents groupes de graffites. Empruntée à différentes sources (latin, grec, gaulois et ?) elle obéissait apparemment (comme il advient très souvent pour l'instrumentum, dans la plupart des langues) à des usages empiriques, consacrés cette fois localement par des professionnels. Nous pensons également avoir montré que les modules réels relevaient de conventions professionnelles plus que du respect rigoureux du système de mesures pris comme référence écrite dans les bordereaux.

Compte tenu des variations mises ici en évidence dans les textes retenus comme exemples, il est probable que la langue quotidienne pratiquée sur les confins de la Narbonnaise par une population en rapport d'affaires avec une grande partie de l'Empire pouvait pour certains être le latin, pour d'autres le gaulois, lc plus souvent sans doute un mélange à composantes variables de latin et de gaulois. La rareté des textes autres que professionnels ou techniques - comme le contrat de location (Mar. 169) ou le plomb magique du Larzac (Lambert, 2002, L-98 p. 251-266) - ne permet pas d'en proposer des exemples pertinents.

\section{LES STRUCTURES PROFESSIONNELLES}

\section{LE PERSONNEL}

En se fondant sur l'analyse du mobilier pour définir le personnel des ateliers de La Graufesenque, on a montré que les marques sur vases/moules soulevaient des questions concernant la structure de la production des produits finis, les relations entre divers participants et le statut socioprofessionnel de ces derniers, présumés libres et plus ou moins autonomes et prospères. Il est apparu aussi que la confrontation entre les estampilles et les graffites, en admettant qu'homonymie implique identité, faisait surgir, au milieu des groupes de noms, socialement et techniquement indifférenciés, recensés dans les comptes à l'occasion d'une fournée, de nombreux inconnus, non attestés par les estampilles et dont l'importance (et la permanence) sont trop souvent minimisćes : ceux de potiers privés, pour des raisons qui nous échappent, du droit de signer les vases ou moules de leur nom.

À côté des équipes à composition variable de fournisseurs de vases se signalaient, d'une part, des magistrats éponymes renouvelables, de l'autre, des potiers dont les assiettes crues servaient de supports aux graffites et dont le nom estampillé se distinguait régulièrement de ceux de la liste inscrite: les (présumés) responsables qualifiés des fournées (voir supra, p. 115). Une autre catégorie de collaborateurs, enfin, a été mise en évidence par R. Marichal : des esclaves dont un fragment de plat (Mar. 169) ${ }^{239}$ restitue partiellement pour l'époque flavienne un compte de location au bénéfice de leur présumé maître (ou maîtresse) : Atelia. Y sont précisés pour un mois (fin juillet-fin août) les noms des intéressés, la nature et la durée des tâches exécutées: manipulations de matières premières [materies, argilla], (transport ?) au marché [mercatus], travail de polissage (?) [samire], effectués sur des sites (?) indéterminés [ad Capuries, Craucinam, Sabros]. Ces esclaves paraissent constituer un personnel temporaire d'appoint ${ }^{240}$ employé à de gros travaux, mais dont les modalités d'embauche demeurent encore inconnues faute de documents plus explicites.

\section{FONCTIONNEMENT DE LA PRODUCTION}

Pièces récapitulatives écrites à loisir, les bordereaux de La Graufesenque, comme l'a montré R. Marichal, n'étaient pas rédigés pendant le chargement. Ils n'avaient sans doute pas non plus de rapports directs avec l'ordre d'enfournement du mobilier à cuire, compte tenu de la diversité de l'organisation des textes découverts au fil des années (voir supra, p. 115 et 126) et pour les raisons techniques que nous avons invoquées. Il s'agissait d'inventaires à usage interne destinés à conserver les traces de fournées alimentées par des groupes de fournisseurs. Les éléments de datation attestent, jusqu'à présent, que ces opérations, organisées entre le printemps et le début de l'automne, se succédaient selon un rythme annuel (calendrier romain), peut-être aussi selon une périodicité quinquennale (calendrier gaulois). Ces textes inscrits dans l'argile crue bénéficiaient des facilités qu'offraient des supports facilement accessibles. Et leur cuisson implique que les listes devaient pendant un certain temps être conservées comme archives. Situées à la jonction entre deux opérations essentielles : la fabrication des vases bruts et leur cuisson, ces pièces comptables intéressaient peut-être, outre les fournisseurs et le responsable de la cuisson, un patron ou mandant, si l'on veut imaginer un système plus hiérarchisé. Mais nous n'avons sur place aucune trace écrite de cette fonction. Répartis globalement, entre 30/40 et Domitien (voire Trajan), sur une durée

239. La signature de l'assiette permet de rapprocher le texte du graffite VB 2.

240. Un petit fragment de compte similaire (Mar. 170) ne permet pas de connaître les personnes intéressées. Ln morceau d'acte d'achat d'un esclave conservé sur un autre plat (Mar. 211) atteste cette pratique à La Graufesenque, sans que l'on sache à quelles fonctions (professionnelles, domestiques?) était destiné cet homme, ni par conséquent s'il y arait une population servile attachée en permanence à la production céramique et quelle était son importance. 
impossible à dater exactement, dans un ordre souvent incertain et séparés par des intervalles inconnus, ces comptes ne permettent donc pas de savoir ce qu'étaient dans la carrière d'un potier les fonctions de maître-fournier : mission temporaire en alternance ou terme d'une progression? La datation plus fine des marques estampillćcs sur les assicttes-supports suffira-t-elle à améliorer la datation relative de ces documents de façon très significative ? Il paraît actuellement présomptueux de le croire.

Autre trait remarquable de cette comptabilité: elle se présente comme une collection d'aide-mémoire, certifiant l'exécution de livraisons préalables au chargement (oneraui / oneratus est), mais ne comporte aucune précision ni sur les conditions d'un engagement entre potiers et fourniers, ni sur les modalités des redevances probables. Versées, comme on l'a soutenu longtemps, par les fournisseurs de vases au maitrefournier pour payer ses services, ces dernières impliquaient pour certains archéologues que les potiers récupéraient leur bien (moins la casse) à la sortie du four. Ce qui aurait représenté un sérieux travail, compte tenu du volume de la fournée, de la mixité possible des piles et du partage de pertes inévitables.

Il paraît plus vraisemblable actuellement, comme le confirment les artisans auxquels nous nous sommes adressés, d'imaginer à l'inverse que les potiers cédaient leurs vases en les livrant et qu'ils étaient rétribués pour leur travail. À quel moment ? Étaient-ils aussi associés pour une part aux aléas de la cuisson, voire aux bénéfices de la commercialisation? La cuisson et la numérotation des bordereaux autorisent à imaginer, sans plus, la possibilité de règlements différés, non leurs modulations.

\section{CADRES JURIDIQUES?}

À La Graufesenque l'usage d'un outil collectif : le four, pour la production massive et normalisée de vaisselles sigillées, impliquait obligatoirement un mode de coordination. Et la standardisation des produits comme l'existence des comptes sont là pour témoigner de relations structurées. Supposer des schémas contractuels entre certains intervenants est possible; on connaissait localement au moins quelques formes romaines du droit (Mar. 169 et 211). Mais poser en postulat la réalité d'un système juridique, surtout en en généralisant la portée, reste délicat. Car, faute de textes, l'organisation en aval et en amont de la cuisson est largement laissée à l'imagination. Si certaines collaborations sont suggérées par les vases moulés et leurs marques, d'autres situations devraient simplement être déduites de l'absence d'informations: rôle des potiers non signataires, gestion des vases sortis du four. Le nombre des acteurs concernés, notre ignorance des formes de la propriété du sol et des ateliers à Condatomagus, tout ce qui nous échappe encore des statuts des potiers et du cumul ou de l'indépendance des multiples fonctions impliquécs par la fabrication et la diffusion sont autant d'incitations à la réserve. Soumettre tout ce personnel à un étroit formalisme juridique ne peut relever que d'hypothèses explicatives. Et les grilles de lecture actuellement proposées paraissent inutilement compliquées, compte tenu de la faiblesse des bases documentaires

Voilà pourquoi il me semble encore expédient d'user de moyens archéologiques, fondés en particulier sur les vases signés, pour accumuler des présomptions : par exemple, de démontrer la coordination entre potiers par les études métrologiques et leurs relations à travers les analyses stylistiques, ou de suggérer les limites de leur implication dans l'industrie et la vente des céramiques, en recourant à l'analyse qualitative des circuits commerciaux.

\section{L'ESTAMPILLAGE COMME MARQUEUR COMMERCIAL : SON INTÉRÊT, SON ÉVOLUTION}

\section{MARQUES ET ARCHÉOLOGUES}

Utiliser les marques pour connaitre la diffusion des vases va de soi, surtout quand la qualité du produit laisse un doute sur son origine, mais ne répond pas aux questions soulevées par la vente. Nous ignorons l'identité du propriétaire des vases, toutes origines confondues, à la fin d'une cuisson, celle du responsable de la vente, et grâce à quels intermédiaires la vaisselle parvenait dans les magasins (souvent associée à d'autres marchandises, comme le révèlent certains convois accidentés). Le seul moyen de montrer une relation, entre un potier, ou un groupe, et une zone réduite de vente, ou une aire indifférenciée, serait de recourir à des évaluations qui font encore largement défaut. Sans doute les résultats des dénombrements différent-ils globalement, comme on l'a déjà montré (Vernhet, 1991 , p. 55-60), en fonction de la période de diffusion : vente limitée, géographiquement et quantitativement, au début et à la fin de la production, explosion de la diffusion à partir du règne de Claude dans les provinces romaines et au-delà. Et on a également mis en évidence, durant cette production de vaisselle de bonne ou assez bonne qualité (20-120/140), la progression générale du marché, ou sa régression progressive en fonction de la concurrence des fabriques d'autres zones de production (par exemple de la Gaule du Centre ou de l'Est en Bretagne, dès le début du $\mathrm{II}^{\mathrm{c}} \mathrm{s}$.).

Mais il serait intéressant aussi d'estimer qualitativement, au moins à titre expérimental, dans des microrégions, les rapports de présence/absence de potiers contemporains identifiés par leurs marques ${ }^{241}$ ou leur style. Régionale, la présence de certains individus pourrait impliquer l'existence de circuits privilégiés mettant en cause des chaînes de production du début à la fin et leur diffusion sélective, c'est-à-dire des relations objectives, sinon directes, du potier jusqu'au vendeur. Indifférenciée elle pourrait prouver, à La Graufesenque, une division horizontale des étapes de l'organisation et l'existence d'une sorte de marché ouvert et global sous la seule responsabilité de commerçants.

\section{UTILISATION ANTIQUE DES SIGNATURES}

Nous avons montré (voir supra, p. 109, 113 et 114), que la vocation publicitaire des signatures sur la vaisselle lisse était globalement très improbable parce qu'inutile. Aussi l'emploi

241. Ces questions m'ont été suggérées à Glanum par les variations dans le temps, apparemment sélectives, de la diffusion des sigillées signées de Ia Graufesenque. Mais ce mobilier était trop peu nombreux, donc trop alcatoire, pour ćtayer solidement des hypothèses. 
par un potier : $L$. Cosius Virilis de cartouches originaux à extrémités semi-circulaires ou triangulaires cloutées, étant un phénomène isolé, relève-t-il encore de la curiosité. Par ailleurs, nous avons vu que l'utilisation plus systématique de marques bien lisibles dans les décors à la fin du $\mathrm{I}^{\mathrm{er}} \mathrm{s}$. était d'abord une mode, et que la mise en page soignée de grosses signatures était un phénomène apparemment limité à quelques potiers, remarquables par la production de formes exceptionnelles ou de décors innovants, tout en fabriquant aussi, sous la même estampille, des modèles parfaitement banals.

De toute façon la connaissance de l'évolution chronologique du contenu et de la forme des signatures dans les officines rutènes laisse encore beaucoup à désirer (faute de publication d'un corpus très attendu) et il n'est pas encore possible de lier globalement ces variations aux modalités des ventes. Par exemple l'interprétation de la dégénérescence à la fin $\mathrm{du} \mathrm{I}^{\mathrm{er}} \mathrm{s}$. des estampilles sur vases non décorés serait à réviser et à interpréter (voir supra, p. 128), car des sceaux usés (et pour nous peu lisibles) témoignaient souvent à leur manière du relâchement dans le travail et de la perte de qualité générale, plutôt que du développement des poinçons réputés pseudoépigraphiques et théoriquement imputables à l'illettrisme.

Plus difficile à expliquer paraît actuellement un phénomène trop négligé: la raréfaction de l'estampillage des tourneurs de vases (correspondant à une sorte de relance de l'entreprise ?). En effet, à partir de 60 environ, une transformation du répertoire des formes décorées est marquée par une réduction du nombre total des modèles: des neuf types, produits au début du règne de Claude, la majorité disparaissent entre la fin du règne de Néron et le début de celui de Vespasien, trois subsistent encore entre 80 et 100 (bol cylindrique, lagène et gourde), une petite tasse et un gobelet flaviens ne connaissant par ailleurs qu'une production réduite et une durée limitée. Et surtout, entre 60 et environ 80 , le bol caréné signé intérieurement (Drag. 29) est remplacé par une forme hémisphérique sans marque interne (Drag. 37) et parfois estampillée sous le décor d'un poinçon non épigraphique, mais figuré.

Parallèlement, parmi les vaisselles lisses classiques ne sont encore bien représentées après 60/70 que trois assiettes, dont deux fabriquées en nombre (Drag. $15 / 17$ et 18/31) et deux tasses tronconiques (Drag. 27 et 33), toutes signées ${ }^{242}$. En revanche, on assiste entre $50 / 60$ et 90 à la création de six nouveaux "services" (dont cinq à marli) comprenant tous, dans différents modules, une coupe et une assiette assortie (voir supra, fig. 69 et 70), et une ou deux petites formes de fantaisie peu attestées. De ces six séries, une seule (E, environ 70-130) porte encore des marques épigraphiques. Une autre (F, 90$140 / 150$ ) est estampillée de rosettes, alors que la série $A$, sans signatures, connaît la plus longue durée (60-140/150) et la plus abondante production.

Cette large disparition de l'estampillage soulève un problème. La pratique de la signature était à La Graufesenque très répandue, en particulier au milieu du $\mathrm{I}^{\mathrm{er}} \mathrm{s}$. Par exemple dans la fosse de Gallicanus elle concernait toutes les formes sauf une et tous les exemplaires de chaque type signé. Les archéologues expliquent d'ordinaire cet usage par le besoin d'identifier des piles de vases crus, livrées séparément au maître-fournier. Dans cette perspective, la suppression délibérée d'un mode général de contrôle impliqua-t-elle des modifications structurelles à l'intérieur du centre de production? La réduction de la place des fournées collectives, voire leur disparition? Le fonctionnement du grand four en tout cas est daté par son environnement entre 80 et $120 / 130$ et nous avons signalé sur certains bordereaux tardifs (Domitien/Trajan) la présence notable de nouveaux inconnus non signataires (voir supra, p. 118). Les contributions des fournisseurs étaient-elles dès lors rétribuées immédiatement? Les moyens de production étaient-ils à cette époque concentrés entre les mains de maîtres d'œuvre qui réglaient leurs comptes avec leurs employés? Le débat est ouvert.

242. Seuls les types Drag. $18 / 31$ et 33 subsistent jusqu'au milieu du II"s. 